This item was submitted to Loughborough's Research Repository by the author.

Items in Figshare are protected by copyright, with all rights reserved, unless otherwise indicated.

\title{
Extensional flow characterisation and extrusion blow moulding of high density polyethylene modified by calcium carbonate
}

PLEASE CITE THE PUBLISHED VERSION

PUBLISHER

(C) Maney

VERSION

VoR (Version of Record)

LICENCE

CC BY-NC-ND 4.0

\section{REPOSITORY RECORD}

Haworth, Barry, and Suparat Jumpa. 2009. "Extensional Flow Characterisation and Extrusion Blow Moulding of High Density Polyethylene Modified by Calcium Carbonate". figshare. https://hdl.handle.net/2134/4228. 
This item was submitted to Loughborough's Institutional Repository (https://dspace.lboro.ac.uk/) by the author and is made available under the following Creative Commons Licence conditions.

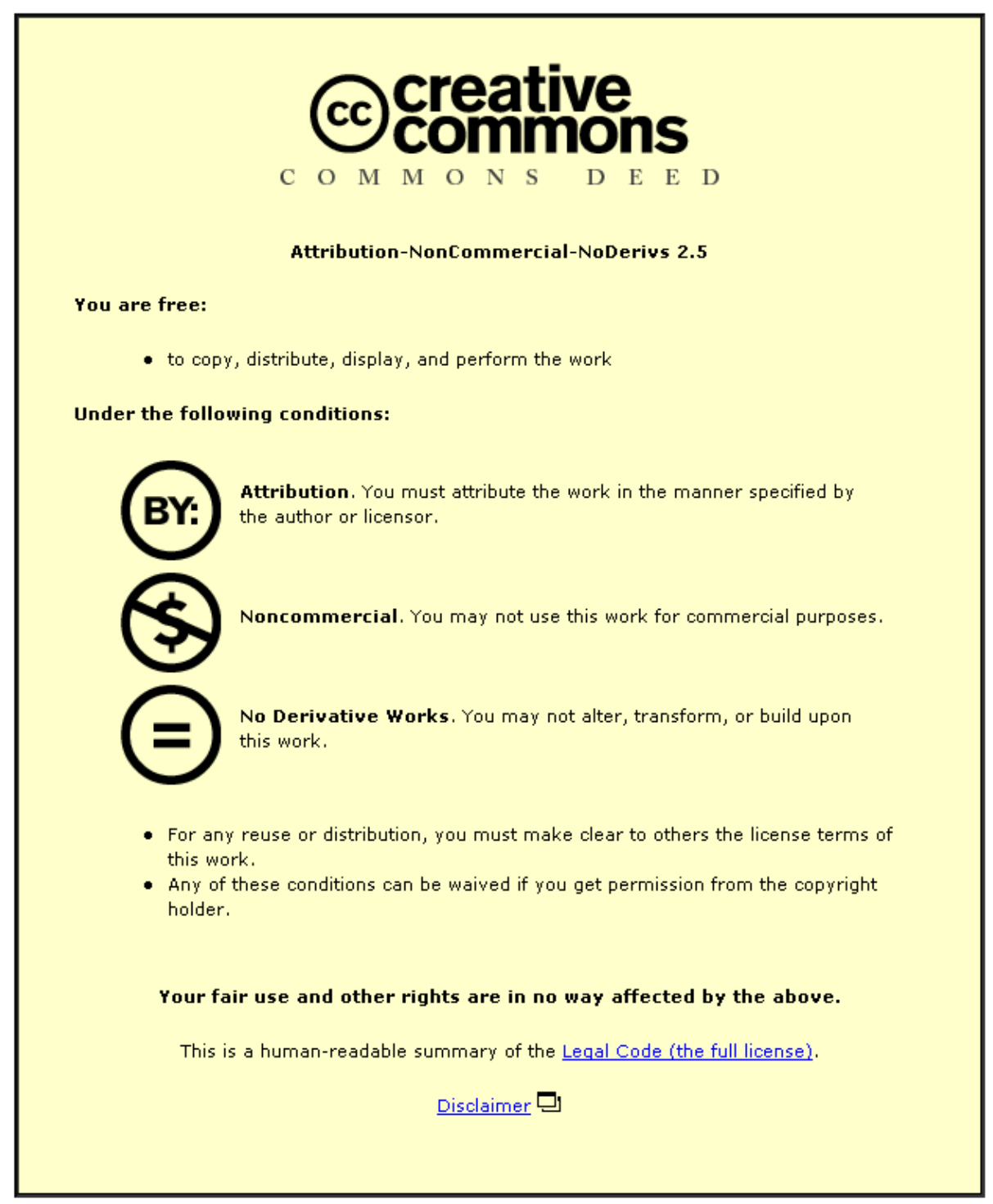

For the full text of this licence, please go to: http://creativecommons.org/licenses/by-nc-nd/2.5/ 


\title{
Extensional flow characterisation and extrusion blow moulding of high density polyethylene modified by calcium carbonate
}

\author{
B. Haworth and S. Jumpa
}

\begin{abstract}
Free surface elongational flow properties, including transient state stress growth and melt rupture data, have been measured on a range of calcium carbonate filled high density polyethylene (HDPE) compounds, using a Rutherford elongational rheometer operating at constant strain rate in the range $0 \cdot 1-6 \cdot 0 \mathrm{~s}^{-1}$. Results show that polymer molecular weight has a strong influence on both tensile stress growth and melt rupture data; increasing elongational strain rate decreases the stress growth coefficient, in all compounds. At any specific elongational strain rate, the stress growth coefficient increases with volume fraction of particulate additives and also when using additives of fine particle size, as a result of packing fraction effects. Acid coatings added at super-monolayer levels influence the viscosity of highly filled compounds, by internal lubrication.

Dynamic extrusion data obtained by experimental blow moulding of calcium carbonate modified HDPE materials show that modifications to melt state shear modulus result in reduced die swell, to an extent determined by filler coating. In combination with die swell, higher extensional viscosity of filled HDPE contributes significantly to enhanced parison sag resistance. Solid state modulus enhancement was consistently observed in calcium carbonate filled HDPE containers and if excellent filler dispersion can be achieved, it is feasible to retain the ductile mode failure of unfilled HDPE when containers are subjected to high velocity impact loads.

$\mathrm{PRC} / 1576$

(C) 1999 IoM Communications Ltd. At the time the work was carried out the authors were at the Institute of Polymer Technology and Materials Engineering, Loughborough University, Loughborough, Leicestershire LE11 3TU, UK. Dr Jumpa is now in the Department of Chemistry, King Mongkut's Institute of Science and Technology Ladkrabang, Chalongkrung Road, Ladkrabang, Bangkok 10520, Thailand. This paper was presented at 'Advances in Blow Moulding' held in Loughborough, UK on 30 June-1 July 1998.
\end{abstract}

\section{INTRODUCTION AND BACKGROUND}

Mineral fillers can be loosely classified as inactive (extenders, or cost reducing additives) or as active (functional) additives, which induce specific changes in properties so that the compound largely meets the requirements demanded of it. ${ }^{1}$ Currently, there is renewed interest in the use of mineral fillers to achieve enhanced processing of thermoplastics, particularly if in addition, some specific physical properties of the product can also be improved. Fillers can change the characteristics of a polymer in two ways: the properties of the particles (size, shape, modulus, and surface energy) can have profound effects on melt state and solid phase mechanical behaviour and also a change in the micromorphology of the solidified polymer may occur, giving rise to differences in the observed solid state properties. For example, increases in addition level of fillers (such as $\mathrm{CaCO}_{3}$ and carbon black, (CB)) in polyalkenic compounds generally improves low strain properties such as tensile modulus, ${ }^{2-5}$ but may decrease properties relating to energy absorption, such as ultimate tensile strength ${ }^{2,6}$ and elongation at break. ${ }^{3,5}$

Additionally, two important technical issues must be considered when using fillers:

(i) the rheological behaviour of the filled polymer (melt state mechanical behaviour), which governs processability and influences microstructure development (ii) the interfacial adhesion characteristics between the particles and the resin matrix, which influence the ultimate mechanical properties of the composite materials.

Incorporation of particulate additives into a resin leads to modified processing behaviour and occasionally to a subsequent deterioration of the ultimate mechanical performance. ${ }^{7}$ However, some important aspects of mechanical behaviour can be significantly enhanced by filler addition; for example, enhanced melt fracture stress occurs when processing filled elastomers. ${ }^{8}$ Toughness enhancement has also been noted in polyalkenes and in brittle matrix polymers, ${ }^{9}$ as long as certain criteria are fulfilled. For example, a critical factor that influences mechanical properties of the compound is the state of particle dispersion in the matrix..$^{10,11}$ To facilitate filler dispersion, the filler is often surface treated with a coating, which acts as a wetting agent by reducing the specific surface free energy of the additive particles. Common coating agents for mineral fillers are fatty acids, from which the acid group reacts onto the filler surface. However, the hydrocarbon chain is unable to react chemically with the matrix and interacts only weakly, producing low bond strength between filler and matrix. ${ }^{12}$ The effect is therefore one of reduced physical interaction, rather than a direct, adhesion promoting phenomenon. In summary, treatment of $\mathrm{CaCO}_{3}$ with stearic 
acid decreases the surface energy of the filler and particle-particle interactions within agglomerated regions. This facilitates filler dispersion and also leads to enhanced mechanical performance of the compounds. ${ }^{13,14}$ Previous research ${ }^{15}$ using coatings of different aliphatic chain length in filled polyethylene has demonstrated that when longer chain coating agents are used to treat the fillers, low strain modulus and yield stress are enhanced but compounds are more prone to brittle mode failure as a result of lower energy absorption.

Improvements in process equipment have been made to enhance efficiency in the compounding of fillers and other particulate additives ${ }^{16}$ and a study of the rheological characteristics of newly formulated compounds is a most important step in examining their behaviour in polymer conversion processes such as extrusion blow moulding. The viscoelastic flow behaviour of particle filled polymer melts depends upon the filler characteristics, the nature of the (polymer/particle and particle/particle) interfaces, the degree of dispersion, and the orientation distribution of the filler particles. ${ }^{17}$ The presence of other additives, even in small quantities, may be crucial in the composite system because they may interfere with the resin/ filler interface ${ }^{18}$ and may also influence the interaction between the compound and machinery surfaces to create a wall slip effect at the flow boundary. ${ }^{19}$ Generally, the presence of filler particles increases the polymer melt viscosity, ${ }^{20}$ with highest levels of viscosity being observed at higher filler content ${ }^{3,5}$ or with smaller filler particle size additives. ${ }^{21}$ A reduction in the viscosity of the compound is sometimes observed when either a coupling or coating agent is present. $^{3,20,21}$

Most studies of the rheological behaviour of particle filled polymer melts reported in the literature involve shear flow, rather than elongational (extensional) flow. This is partly due to perceived experimental difficulties and also a lack of recognition of the importance of elongational flows in polymer processing. ${ }^{22}$ Elongational deformation is often apparent as a free surface flow, i.e. there is no boundary between the melt and the rheometer (viscometer) walls. This is in contrast to shear deformation, in which the melt is in contact with and is sheared between the rheometer walls. ${ }^{23}$ Elongational flows also occur as constrained flows, e.g. in converging sections of extrusion dies. ${ }^{24}$ The elongational mode of deformation is observed in several phases of blow moulding processes, including low strain rate gravimetric loading (in which the elongational stress tends to deform the parison vertically, along its principal axis: parison sagging) and during the inflation phase, which is a high strain rate deformation. Therefore, to achieve satisfactory blow moulded products, which depends upon both material distribution and polymer properties, knowledge of rheological properties is required to include both shear and elongational modes of deformation.

The research reported in the present paper features a uniaxial elongational rheometer, the Rutherford elongational rheometer (RER), which provides free surface deformation, and was principally based on an instrument designed by Münstedt. ${ }^{25}$ It was first devel- oped by Smoker ${ }^{26}$ who studied the elongational flow behaviour of low density polyethylene (LDPE) for film blowing applications. Further modifications of the RER apparatus were subsequently introduced by Axtell and Haworth ${ }^{27,28}$ who used the RER to study the viscoelastic behaviour of poly(ethylene terephthalate) (PET) in the rubbery region at temperatures above the primary glass transition temperature $T_{\mathrm{g}}$, to simulate the stretch-blow moulding process. Other applications have been focused upon rigid PVC compounds, to simulate elongational deformation and flow in processes such as thermoforming, and bubble formation in foam extrusion. ${ }^{29}$ Very little previous research has been reported relating to the elongational deformation and rupture of filled polymer melts. It has been reported ${ }^{30}$ that in fibre filled polypropylene compounds, the elongational viscosity is not only a function of time but also of strain rate. Other work$\mathrm{ers}^{21}$ have reported that the elongational viscosity of $\mathrm{CaCO}_{3}$ filled polystyrene increases with filler content and/or reduction of particle size.

This research focuses on composite systems of high molecular weight, high density polyethylene (HDPE) resins compounded with a number of $\mathrm{CaCO}_{3}$ fillers varying in particle size, surface coating, and addition level. The filler coatings include stearic acid, which is a widely used coating agent in filled polyalkenic compounds, and an acid terminated polyethylene (ATPE), a newly developed material based upon low molar mass polyethylene chains terminated at one end with an acid group. Since similar compounds are being developed specifically for applications in which their processability is important, the overall objective of the research is to characterise the elongational deformation properties of $\mathrm{CaCO}_{3}$ modified HDPE and to relate these properties to the processing behaviour and selected product attributes of containers manufactured by extrusion blow moulding.

\section{ELONGATIONAL RHEOMETRY: OVERVIEW OF FREE SURFACE DEFORMATION}

In polymer processing, the stress distributions that create the deformation required for shaping are also responsible for structure development, together with the thermal history during the cooling phase. Appropriate polymer properties relevant to the thermomechanical history must be carefully characterised offline, if process simulation and modelling techniques are accurately to simulate real time manufacturing processes. While this holds true for simple polymer systems, interrelationships between processing, structure development, and properties hold even greater significance (and are made more complex) by the addition of significant quantities of particulate additives, in heterogeneous polymer composites. This is notable when processing thermoplastics modified by particulate fillers, for which the particles (and other additives such as coatings and coupling agents) are known to have a strong influence on different aspects of flow and deformation behaviour. ${ }^{12}$

The flow mechanism is also important in this context. For example, if a process requires shear flow properties of polymer melts between fixed boundaries (constrained flows), the influence of filler coatings 
on external lubrication becomes highly significant. In contrast, wall slip behaviour is clearly irrelevant to free surface extensional deformations such as parison sag and inflation, in extrusion blow moulding.

The processing advantages afforded by filled thermoplastics are currently being exploited on an increasing scale. However, characterisation of the elongational deformation and flow properties of these materials has received relatively little coverage in relevant scientific journals. For the research studies that are reported in this paper, free surface deformations were applied under conditions of constant extensional strain rate. The RER used in the research is a free surface deformation elongational rheometer, similar in principle to an instrument designed previously, ${ }^{25}$ which measures force and extension as a function of experimental time, in order to compute the rheological parameters defined below. The motion involves deformation between coaxial clamps, one of which moves relative to the other, according to the pre-set conditions. Some subsequent modifications to the original design and updates to the data capture and processing methods have been detailed in other publications. ${ }^{31,32}$ A review paper by Meissner ${ }^{33}$ has provided an appropriate summary of research carried out using this type of equipment.

When this design of rheometer is operating under closed loop, constant strain rate conditions, it can be shown that the specimen length varies with time according to

$$
L_{\mathrm{t}}=L_{0} \exp \left(\dot{\varepsilon}_{\mathrm{H}} t\right)
$$

where $L_{0}$ is the initial specimen length, $\dot{\varepsilon}_{\mathbf{H}}$ is the Hencky (logarithmic) strain rate, and $t$ is time. This expression may be rewritten in terms of axial velocity $V_{\mathrm{t}}$

$$
V_{\mathrm{t}}=\dot{\varepsilon}_{\mathrm{H}} L_{0} \exp \left(\dot{\varepsilon}_{\mathrm{H}} t\right)
$$

Since this type of experiment involves the attainment of large strains, the stress function must account for the reduction in specimen cross-section that occurs. It may be shown that the true extensional stress $\sigma_{\mathrm{E}}$ can be expressed in terms of transient length $L_{\mathrm{t}}$ and axial force $F_{\mathrm{t}}$ by

$$
\sigma_{\mathrm{E}}=F_{\mathrm{t}} L_{\mathrm{t}} / A_{0} L_{0}
$$

where $A_{0}$ is the initial specimen cross-sectional area.

In a constant elongational strain rate test, motion with constant stretch history is achieved and this type of deformation is called steady, simple (uniaxial) elongation. When the elongational strain rate is held constant, starting at time $t=0$, the tensile stress increases as a function of time. Usually, the results of a tensile stress growth experiment are interpreted in

Table 1 Nominal molecular weight data for HDPE

\begin{tabular}{lcc} 
& polymers used in rheological analysis \\
\hline Polymer & $\begin{array}{l}\text { Molecular weight, } \\
\mathrm{g} \mathrm{mol}^{-1}\end{array}$ & $\begin{array}{l}\text { Molecular weight } \\
\text { distribution }\end{array}$ \\
\hline HDPE-A & 350000 & $14 \cdot 3$ \\
HDPE-B & 160000 & 8.8 \\
HDPE-C & 95000 & 3.5 \\
HPDE-D & 110000 & $7 \cdot 9$ \\
\hline
\end{tabular}

terms of a tensile stress growth coefficient (TSGC) $)^{34}$ determined as

$$
\lambda\left(\dot{\varepsilon}_{\mathrm{H}}, t\right)=\sigma_{\mathrm{E}}(t) / \dot{\varepsilon}_{\mathrm{H}}
$$

If and when the tensile stress levels out to a constant value, the limiting tensile stress growth coefficient represents the elongational viscosity $\lambda$

$$
\lambda=\lambda\left(\dot{\varepsilon}_{\mathrm{H}}\right)=\lim _{\mathrm{t} \rightarrow \infty}\left[\lambda\left(\dot{\varepsilon}_{\mathrm{H}}, t\right)\right]
$$

In this paper, the influence of some particulate $\mathrm{CaCO}_{3}$ additives on the extensional flow and deformation of some high molar mass HDPE polymers are considered and analysed using the RER operating in constant strain rate mode according to the principles defined above.

\section{MATERIALS AND EXPERIMENTAL}

\section{HDPE polymers}

A range of Rigidex ${ }^{\circledR}$ HDPE polymers differing in molecular weight $M_{\mathrm{w}}$ and distribution were supplied by BP Chemicals Ltd (Grangemouth, UK) and have been coded as shown in Table 1 . Grades A, B, and D have variable molecular weight, but with a similar molecular weight distribution. The effect of changing molecular weight distribution can be made by comparison of grades $\mathrm{C}$ and $\mathrm{D}$, which have a similar molecular weight. All molecular weight data are nominal values, obtained using high temperature gel permeation chromatography.

\section{Fillers and coatings}

The $\mathrm{CaCO}_{3}$ fillers were supplied by ECC International (St. Austell, UK) and varied in terms of particle size distribution, and coating type/addition level. The materials in the Microcal ${ }^{\circledR}$ range are high purity grades, derived from Italian marble. Further details of these materials are given in Table 2. Microcal ${ }^{\circledR}$ C110S was supplied with stearic acid coating applied by the manufacturer, whereas all organoacid coatings on as supplied (uncoated) fillers were applied by an in house, dry blending process. This technique uses a high speed Fielder batch mixer, with process conditions defined by monitoring the time dependent filler-coating reaction using FTIR in diffuse reflectance (DRIFT) mode and has been described in detail elsewhere. ${ }^{15,35}$ The ATPE polymer

\begin{tabular}{|c|c|c|c|}
\hline $\mathrm{CaCO}_{3}$ filler & $\begin{array}{l}\text { Particle size, } \\
\mu \mathrm{m}\end{array}$ & Coating & $\begin{array}{l}\text { BET } \\
\text { surface } \\
\text { area, } \\
\mathrm{m}^{2} \mathrm{~g}^{-1}\end{array}$ \\
\hline RL06083 & 0.55 & Uncoated & $17 \cdot 3$ \\
\hline Microcal C110 & $1 \cdot 80$ & $\begin{array}{l}\text { Stearic acid, ATPE } \\
\text { (various levels) }\end{array}$ & $4 \cdot 7$ \\
\hline Microcal C110S* & $1 \cdot 71$ & Stearic acid & $6 \cdot 5$ \\
\hline Microcal C140 & $10 \cdot 82$ & Uncoated & $1 \cdot 2$ \\
\hline
\end{tabular}
(grade AC X495) has an approximate molar mass of $4550 \mathrm{~g} \mathrm{~mol}^{-1}$, as determined from its acid number of

Table 2 Measured particle size data of $\mathrm{CaCO}_{3}$ fillers* and details of applied coatings

* All fillers were dry coated using the techniques described, except Microcal C110S, which was coated at source by the material supplier, ECC International. 
$12 \cdot 4 \mathrm{mg} \mathrm{KOH} / \mathrm{g}$, and was supplied by Allied Signal Corporation (Belgium).

\section{Compounding}

All HDPE polymers were initially combined with $40 \%$ (nominal, by weight) of $\mathrm{CaCO}_{3}$, using a co-rotating twin screw extruder supplied by APV Industrial Extruder Division (Newcastle Under Lyme, UK). The extruder has a screw diameter of $30 \mathrm{~mm}$ and a nominal length/diameter ratio of $30: 1$; overall output rate was $\sim 12 \mathrm{~kg} \mathrm{~h}^{-1}$ in all cases and screw design was optimised for 'single stage' dispersive mixing. In addition, $\mathrm{HDPE}-\mathrm{CaCO}_{3}$ compounds were prepared as a function of filler content using polymer HDPE-B, up to a maximum additive volume fraction of $\sim 0.30$. In all cases, measurements of extruder torque (related to specific energy input) and melt pressure (at the die entry region) were made when steady state processing was achieved, in order to generate real time measurements with which to characterise dispersive mixing.

\section{Elongational rheometry}

The RER was used in constant strain rate mode, for all rheological analyses reported in this paper. Specimens were prepared by die cutting from sheets (thickness $1.0-1.5 \mathrm{~mm}$ ) which were compression moulded at $200^{\circ} \mathrm{C}$, using techniques described elsewhere. ${ }^{32,35}$ Most of the rheological analyses were carried out at 150 or $170^{\circ} \mathrm{C}$ using a constant elongational strain rate range up to $6 \cdot 0 \mathrm{~s}^{-1}$. This operating mode requires the crosshead velocity to increase exponentially throughout the test duration (equation (2)), thus the machine is operating to a closed loop mode of control. Raw data (force and extension) were collected as a function of time, at a pre-set collection frequency and processed into appropriate rheological parameters (see previous section) using the machine software.

\section{Extrusion blow moulding}

To examine an application for the rheological measurements made on the HDPE composites, the research programme was extended to include process measurements made on a commercial extrusion blow moulding unit (Hayssen Monoblow 2070, $45 \mathrm{~mm}$ diameter screw), operating at $190^{\circ} \mathrm{C}$. Dynamic flow characteristics were measured by relating machine output to screw speed and shear viscosity. Low strain rate viscous flow characteristics in tension were studied by measurements of time dependent parison deformation; extension times required to achieve a series of vertical deformations were recorded. Taking diametric and thickness measurements of extruded parisons quench cooled in water, melt elasticity and die swell were investigated. Since elastic recovery is time dependent, the location of all measurements ( $50 \mathrm{~mm}$ below the cut off position) was kept constant.

\section{Structure and physical properties}

While keeping all independent variables constant other than compound formulation, the dependence of container properties on extensional deformation applied during processing was included in the research. Ambient temperature mechanical property measurements were obtained firstly in tension at low deformation rates, using a JJ Lloyd vertical tensometer operating at a crosshead speed of $20 \mathrm{~mm} \mathrm{~min}^{-1}$. In addition, the response to high strain rate impact loading conditions was determined using a Rosand IFW5 instrumented impact unit, testing rectangular specimens cut from 'as processed' wall sections of containers. A test temperature of $-40^{\circ} \mathrm{C}$ was selected, with $60 \times 60 \mathrm{~mm}$ specimens pre-cooled using a liquid nitrogen supply to a constant temperature environmental chamber. This temperature was known to lie close to a ductile-brittle transition for these composites and was selected because the test specimen thickness was too low to enable geometry independent, brittle mode fracture data to be obtained.

Finally, the respective influences of polymer crystallinity, crystalline texture, and orientation were examined using differential thermal analysis (DTA) and by optical microscopy (polarised light mode), respectively.

\section{RESULTS AND DISCUSSION}

\section{Free surface elongational rheometry}

Raw stress growth and strain data were developed from transient measurements of extensional force and distance, as a function of deformation time. The RER measurement principles and procedures, including recent upgrades made to data collection and associated software, have been described in a recent publication. ${ }^{32}$ Some selected results from the overall research programme are presented below, with comments relating to the influence of specific parameters. In most cases, a tensile 'stress growth coefficient' (transient extensional stress, divided by strain rate: see equation (4)) has been quoted rather than extensional viscosity, since steady state conditions were not achieved.

\section{General deformation behaviour of $\mathrm{HDPE}-\mathrm{CaCO}_{3}$ filler}

For free surface, extensional flow data plotted as stress growth function $v$. time (Fig. 1), a master curve is often obtained for a given polymer grade, with a series of departure points from this curve at positions dependent upon strain rate. This effect has been highlighted in a recent publication containing free surface extensional deformation data from different sources, using a range of experimental techniques. ${ }^{36}$ The phenomenon is often loosely referred to as 'strain hardening' and is related to the relaxation behaviour of the entangled molecular network, relative to the stress developed in the flow field. The general deformation behaviour of HDPE was found to be molecular weight dependent, with the highest molar mass polymers requiring greater stress (hence a higher stress growth coefficient) to achieve an equivalent deformation (Fig. 1). These test data represent analyses carried out at the maximum strain rate of $6.0 \mathrm{~s}^{-1}$, so that the test timescales are extremely short. Despite this, there is evidence of different deformation regimes as the tests proceed.

In the initial part of the test the deformation develops as the moving crosshead accelerates; the degree of scatter is relatively high initially, in view of 


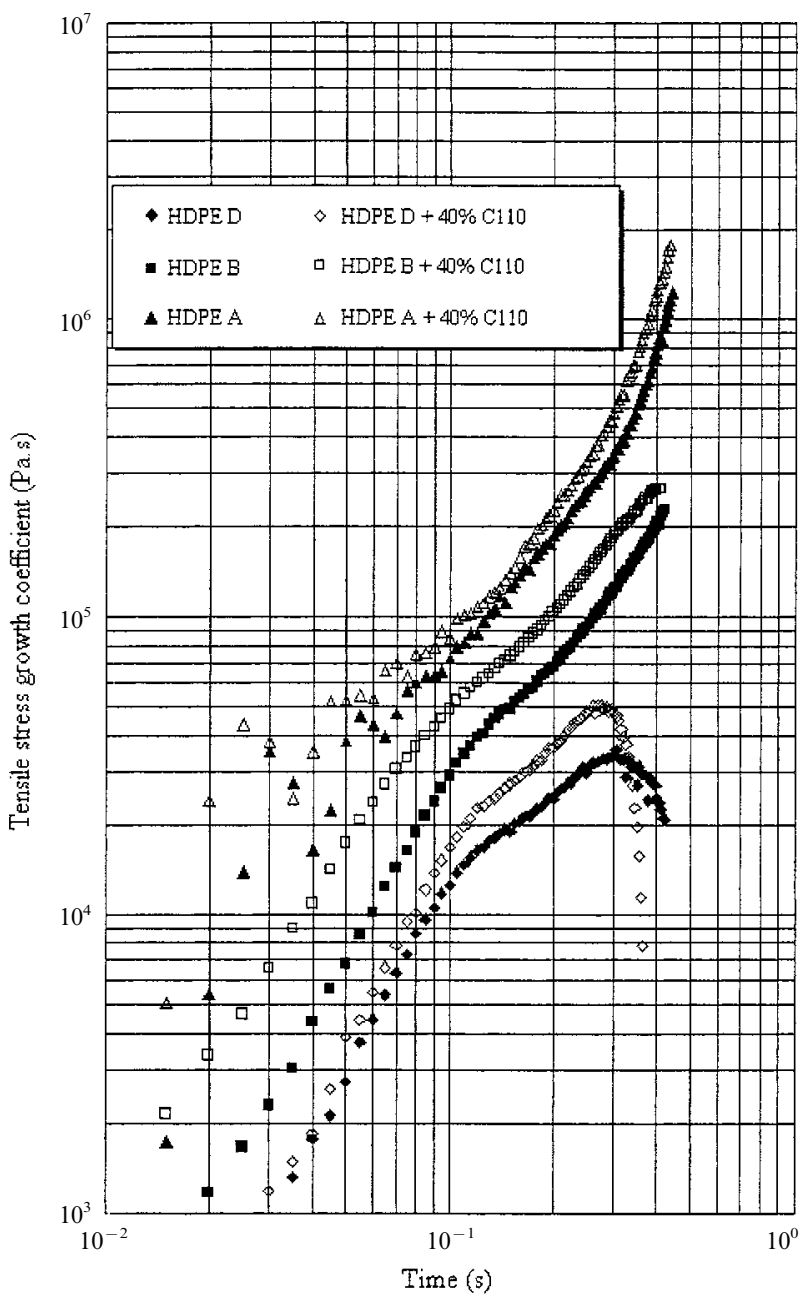

1 Elongational deformation behaviour of HDPE compounds; (closed symbols) unfilled and (open symbols) containing $40 \% \mathrm{C}_{110 \mathrm{CaCO}_{3} \text { filler }}$ at $150^{\circ} \mathrm{C}$ and strain rate $6.0 \mathrm{~s}^{-1}$ showing effects of molecular weight (see also Table 1)

the influence of potential time lag effects over the very short timescales involved. The deformation then becomes more uniform with a reduction in gradient becoming apparent. A more marked decrease in deformation force (hence TSGC) occurs if tensile melt rupture occurs, as in HDPE-D (see below). Otherwise, a sharp increase in gradient is eventually detected (HDPE-A, Fig. 1), the position of which depends upon the elongational strain rate. ${ }^{36}$ The experiments shown in Fig. 1 were carried out at a constant strain rate of $6 \cdot 0 \mathrm{~s}^{-1}$, so that only the highest molar mass material (HDPE-A) showed the strain hardening effect before the end of the test, where maximum extension was attained. Therefore it can be concluded that the incidence of 'strain hardening', induced by a viscoelastic transition and characterised by an increased gradient on the TSGC-time plot, is sensitive to HDPE molecular weight.

The influence of particulate additives, rigid 'pseudospherical' $\mathrm{CaCO}_{3}$ particles in this case, is also clear from Fig. 1. While the qualitative deformation mechanisms remain unchanged when $40 \mathrm{wt}-\%$ of the $2 \mu \mathrm{m}$ C110 particles are added to the HDPE compounds, there is a consistent increase in TSGC data for

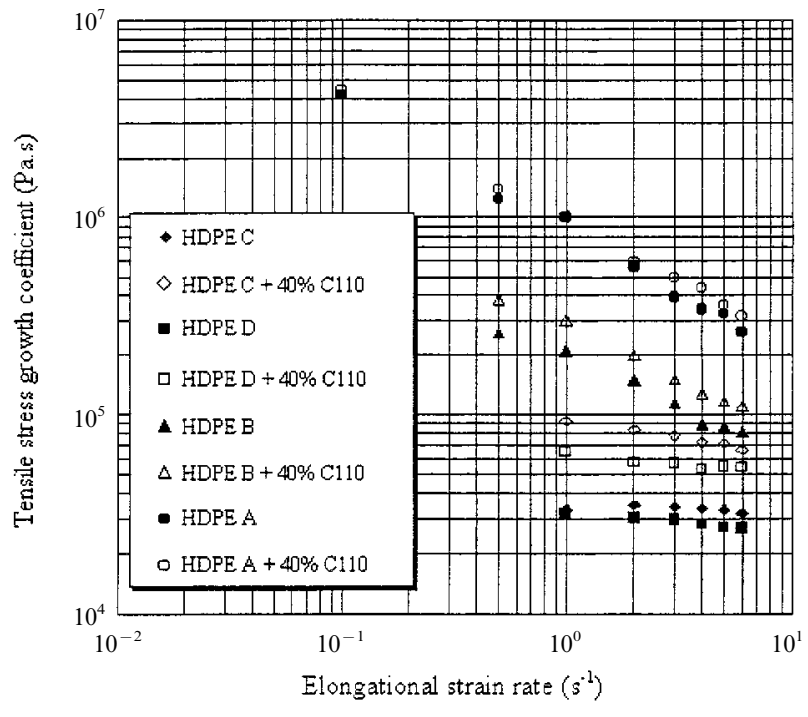

2 Tensile stress growth coefficient $v$. elongational strain rate for HDPE compounds; (closed symbols) unfilled and (open symbols)

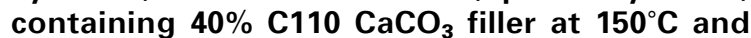
Hencky strain of 1.5 showing effects of molecular weight

each polymer grade, over the entire test timescale. Additional filler particle effects (particle size, acid coatings, and volume fraction) are considered in more detail below.

In view of the rate sensitive effects and the desirability of generating extensional flow data that can be used in process simulation, it is useful to express deformation and viscosity data as a function of strain rate. For purposes of comparability, the TSGC is expressed in this way, as measured at a specific Hencky (logarithmic) strain, in this case for an extensional strain of 1.5 (Fig. 2). This corresponds to specimen length of $72 \mathrm{~mm}$ (extension ratio $L / L_{0}$ of 4.48 ) and a test timescale of $0.25 \mathrm{~s}$, when testing at $6 \cdot 0 \mathrm{~s}^{-1}$ strain rate). While accepting that these data are transient, it has been confirmed that the HDPE polymers and compounds are tension thinning in their response to a variable strain rate, an effect analogous to pseudoplasticity in steady state shear flows. This is in agreement with previous studies on linear polyethylenes ${ }^{37,38}$ and molecular weight influences not only the quantitative values of TSGC, but also the overall shape of the deformation plots. ${ }^{38}$ The higher the molar mass, the greater is the strain rate sensitivity (Fig. 2).

In Fig. 2, the respective influences of molecular weight and $\mathrm{CaCO}_{3}$ particles are comparable. Over the range of variation that has been included in the study, the molecular characteristics of the linear polymers are more dominant than the addition of $40 \%$ particulate filler. Variations due to molecular weight distribution (between HDPE grades $\mathrm{C}$ and D) are relatively small, although the polymer with a broad molecular weight distribution (HDPE-D) has a lower TSGC at a given elongational strain rate. The increase in deformation resistance due to interaction with $\mathrm{CaCO}_{3}$ particles is clearly less significant for the HDPE polymers of highest molar mass (grades A and $\mathrm{B})$.

Plastics, Rubber and Composites 1999 Vol. 28 No. 8 


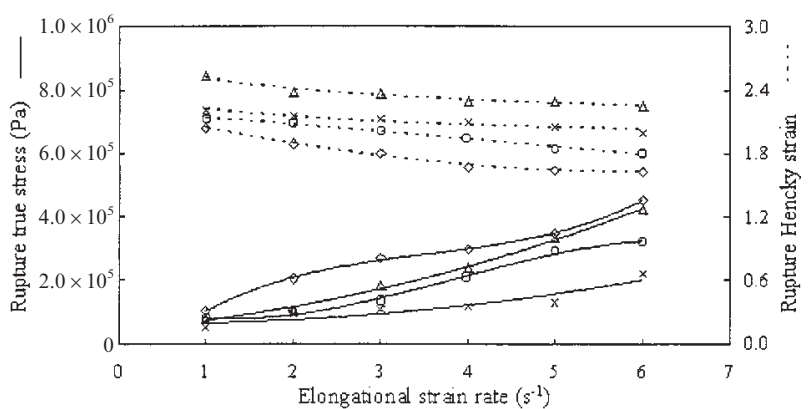

3 Melt rupture data; (-) true stress and (-- - ) Hencky strain for $(\triangle)$ HDPE-C, $(\diamond)$ HDPE-C + 40\% C110, $(\times)$ HDPE-D, and ( $\square)$ HDPE-D + $40 \%$ C110

\section{Melt rupture data}

Under the conditions studied (strain rate of $6.0 \mathrm{~s}^{-1}$ at $150^{\circ} \mathrm{C}$ ), only the two HDPE polymers of lowest molecular weight (HDPE-C and HDPE-D) suffered extensional melt rupture (Fig. 1), as discussed above. Similar results were also derived from other tests at lower strain rates, so that more specific trends relating melt rupture to molecular weight distribution and strain rate are illustrated in Fig. 3. The low molar mass polymer with higher molecular weight distribution, HDPE-D, gave the lowest stress and extension at rupture, over the entire strain rate range. For each polymer, incorporation of $40 \%$ uncoated C110 filler increases rupture stress but reduces the Hencky strain, an effect which can be seen qualitatively (for HDPE-D at $6.0 \mathrm{~s}^{-1}$ ) in Fig. 1. The narrow molecular weight distribution grade (HDPE-C) polymer shows greater overall extensibility, as reported previously for polypropylene. ${ }^{39}$ However, the incorporation of $\mathrm{CaCO}_{3}$ decreases rupture strain to a greater extent in this polymer (Fig. 3).

A discernible viscoelastic transition occurs immediately before melt rupture, for the lowest molar mass grade shown in Fig. 1. If the response is predominantly viscous, specimen dimensions and deformation force reduce significantly prior to the onset of melt rupture, ${ }^{29}$ this results in an apparent maximum in the TSGC-time plots, followed by a sudden reduction in force, which parallels the incidence of rupture. This rupture mechanism involves a necking effect which has been observed previously for unfilled polyalkene melts ${ }^{37,39}$ and is consistent with the tension thinning deformation characteristics, since the localised strain rate increases markedly throughout the rupture process. It has been suggested that the qualitative difference between localised viscous necking (due to tension thinning) and the response of strain hardening elastic fluids can be interpreted using a modified Considere analysis, commonly used to predict stable yielding in solid state polymers. ${ }^{40}$

Overall, these results confirm the suitability of high molecular weight HDPE grades for the blow moulding process, for which a high extensional viscosity contributes to a high resistance to parison sagging, and gives high resistance to melt state rupture during the high deformation rate parison inflation phase.

\section{Filler volume fraction}

Having initially established the overall effect of introducing $40 \% \mathrm{CaCO}_{3}$ particles to the HDPE melts,

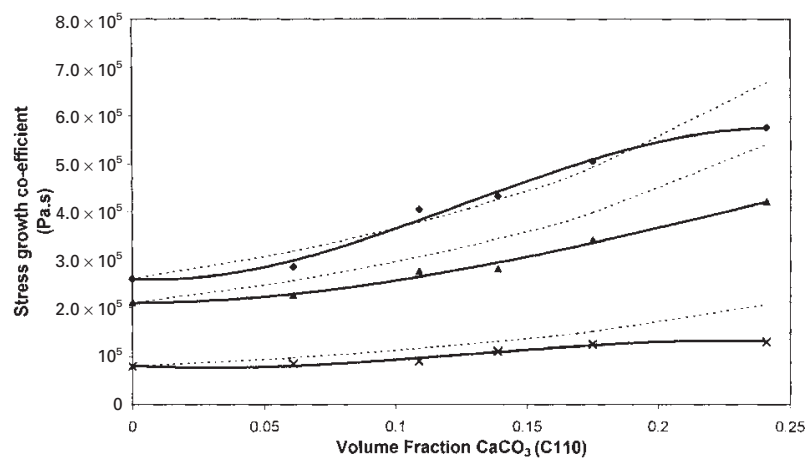

4 Effects of $\mathrm{CaCO}_{3}$ volume fraction and elongational strain rate on tensile stress growth coefficient of $\mathrm{HDPE}-\mathrm{CaCO}_{3} \mathrm{compounds}\left(150^{\circ} \mathrm{C}\right.$, Hencky strain 1.5): (-tions obtained using equation (6) with assumed $\phi_{\text {MAX }}$ of 0.64 ; elongational strain rate $=(\diamond) 0.5$, (A) 1.0 , and $(x) 6.0 \mathrm{~s}^{-1}$

more detailed investigations were carried out by systematically varying the volume fractions of filler added to one specific polymer, HDPE-B. A series of ashing tests was carried out to determine the exact filler content levels, following compounding. ${ }^{35}$ In the results that follow (Fig. 4), it is these exact volume fraction data that are referred to, rather than the nominal values. The maximum filler addition was $54 \mathrm{wt}-\%$, which corresponds to a volume fraction of $0 \cdot 29$, when calculated using solid state density data for HDPE-B.

All the TSGC data are strain rate sensitive (Fig. 2), so that the effects of extension rate are also included in the data summary (Fig. 4). The linear ordinate in this figure clarifies that the viscosity increase induced by greater amounts of filler is most marked under low strain rate conditions. The trends are non-linear, as predicted theoretically by relative viscosity $\left(\lambda_{\mathrm{f}} / \lambda_{0}\right)$ data using an equation of the form given below, according to Maron-Pierce ${ }^{41}$ or Quemada ${ }^{42}$

$$
\lambda_{\mathrm{f}} / \lambda_{0}=\left[1-\left(\phi_{\mathrm{f}} / \phi_{\max }\right)\right]^{-2}
$$

where $\phi_{\mathrm{f}}$ represents filler volume fraction and $\phi_{\max }$ is the maximum filler volume fraction ('packing fraction') that can be incorporated in the matrix. For the data shown in Fig. 4, the highest experimental volume fraction $\phi_{\mathrm{f}}$ is $\sim 0 \cdot 24$, if a melt state density of $750 \mathrm{~kg} \mathrm{~m}^{-3}$ is assumed for HDPE. Use of the inverse square model in equation (6) gives a good fit to the experimental data obtained at the lowest strain rate $\left(0.5 \mathrm{~s}^{-1}\right)$, if a maximum packing fraction $\phi_{\max }$ of 0.64 (random close packing of one size, spherical particles) is used. ${ }^{42}$ However, overestimates of relative elongational viscosity are predicted theoretically, especially at high volume fractions, for the data at high strain rate. These comparisons should not be overinterpreted however, since there are several factors that contribute to differences between theory and practice:

(i) an accurate experimental value of the maximum packing fraction is required for any combination of polymer melt and particulate filler; it has been recognised that this parameter is also strongly dependent upon surface treatment $^{42}$ 


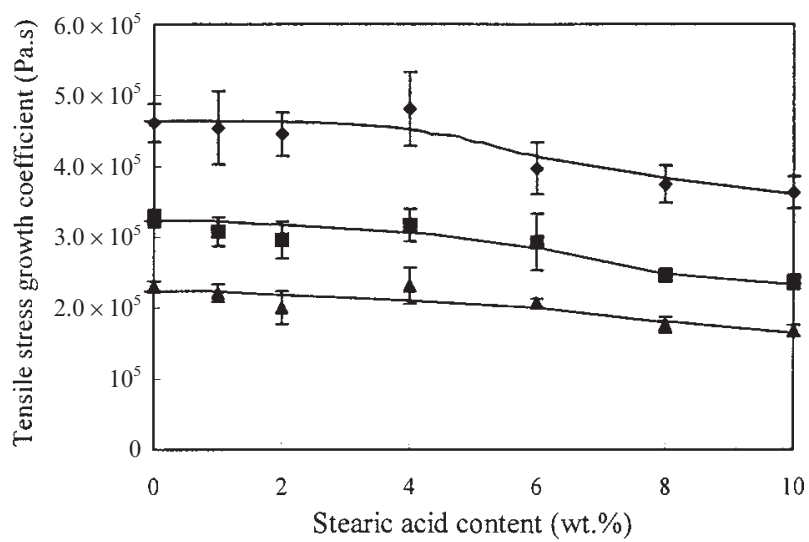

5 Tensile stress growth coefficient $v$. filler coating (stearic acid) concentration, for HDPE-B-CaCO compounds at $150^{\circ} \mathrm{C}$; elongational strain rate $=$ $(\diamond) 0.5$, ( 1.0 , and $(\Delta) 2 \cdot 0 \mathrm{~s}^{-1}$

(ii) the effective extensional deformation, and therefore strain rate, increases with the concentration of particulate modifier, which is likely to induce interactive effects on the experimentally determined stress growth data

(iii) transient data - all stress growth data are from reference positions at a fixed Hencky strain in constant strain rate tests and do not represent steady state values.

The practical significance of the results in Fig. 4 is that the addition of $\mathrm{CaCO}_{3}$ offers greater resistance to parison extension under gravitational forces, but has a lesser influence on the blowing phase (parison inflation). Aspects of this research that relate rheological data in an applied context to the extrusion blow moulding process are considered in more detail in the section on the rheology and processing of extrusion blow moulding.

\section{Filler coatings}

Stearic acid and ATPE coatings were used on $\mathrm{CaCO}_{3}$ filler (grade $\mathrm{C} 110$ ), for selected samples at a specific addition level in HDPE-B. Incorporation of $40 \%$ filler $(0 \cdot 16$ volume fraction in the melt state) increases the TSGC of HDPE significantly, regardless of the addition level of stearic acid. Even if the coating is applied to the filler particles in quantities exceeding the monolayer level, there is only a marginal effect on the data and trends in conventional TSGC-time or TSGC-strain rate plots. To enhance clarity therefore, stress growth coefficient has been plotted against coating concentration over a range of extensional strain rates, for data at a fixed Hencky strain of $1 \cdot 5$, in the relevant plot (Fig. 5).

When the HDPE compounds contain $\mathrm{CaCO}_{3}$ particles coated by stearic acid at concentrations up to $10 \mathrm{wt}-\%$ (relative to filler), the TSGC decreases systematically with coating concentration at each extension rate (Fig. 5). However, while these trends are observed consistently, the magnitude of the effect is relatively small in comparison with the influence of HDPE molecular weight and extensional strain rate, which have been discussed above. The gradients of the individual plots in Fig. 5 increase significantly at coating levels that exceed the monolayer addition, which is $\sim 2 \%$ for $\mathrm{C} 110$ filler. This effect is related to

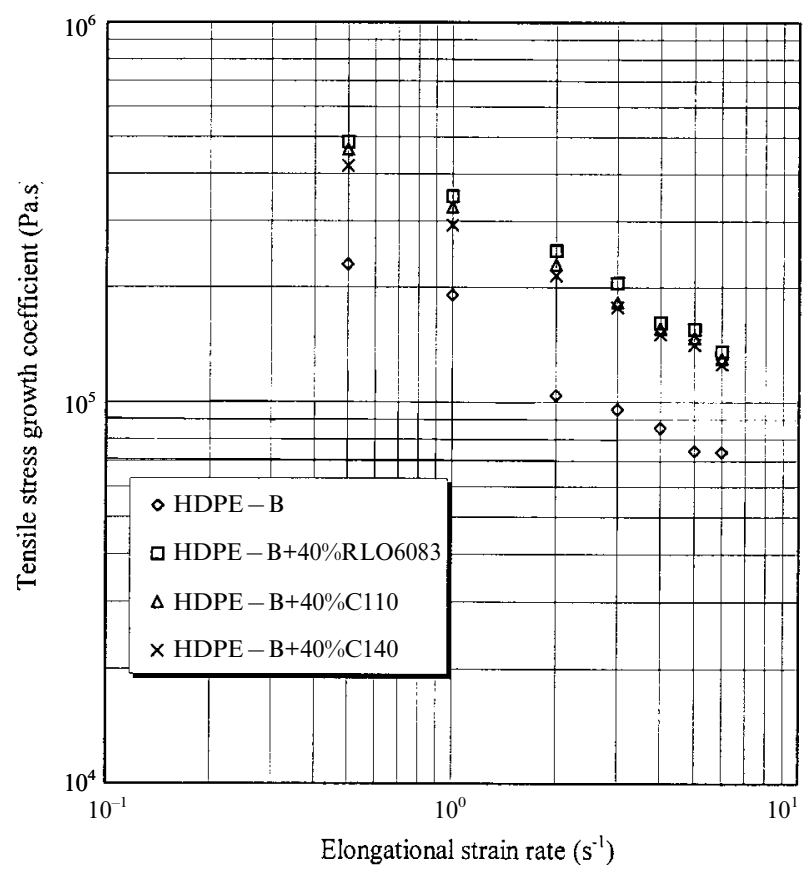

6 Tensile stress growth coefficient $v$. elongational strain rate for HDPE-B compounds $\left(150^{\circ} \mathrm{C}\right.$, Hencky strain 1.5) both unfilled and containing nominal $40 \% \mathrm{CaCO}_{3}$ fillers of varying particle size see also Table 2

a form of internal lubrication, induced by the presence of calcium stearate salt crystals formed by the coating reaction, which tend to detach from the filler particles during intensive dry mixing. ${ }^{35}$ As an additional, or alternative, source of lubrication, free (unreacted) stearic acid has been detected in $\mathrm{CaCO}_{3}$ mixes by DRIFT for stearic acid levels of $4 \%$ or greater. ${ }^{35,43}$

Organic fatty acids therefore have a more important role in enhancing filler dispersion at the mixing stage, rather than a direct rheological influence during extensional deformation. The results in Fig. 5 are in contrast to equivalent rheological studies carried out using constrained shear flows within fixed flow boundaries (in moulds, capillary dies, etc.), for which the presence of free fatty acid (or equivalent acid salts) often results in a significant reduction in polymer viscosity, due to external lubrication.

\section{Particle size}

The addition of $40 \%$ of any $\mathrm{CaCO}_{3}$ filler to HDPE-B gives a qualitatively similar response in extensional flow, as shown in Figs. 1 and 2, with increases in TSGC being consistently observed. In addition, however, filler particle size has been shown to be an important and influential characteristic, with fine particle size additives increasing this parameter to the greatest extent. Figure 6 illustrates these effects and also indicates strain rate sensitivity, with the greatest differences occurring at low strain rate. In order to clarify the apparent trends observed, the data in Fig. 6 have been represented in histogram format (Fig. 7), in which the sensitivity of extensional deformation to both particle size and strain rate is apparent.

Fine particles are characterised by a greater specific surface area (see the Brunauer-Emmett-Teller surface area data in Table 2), which is clearly an important 


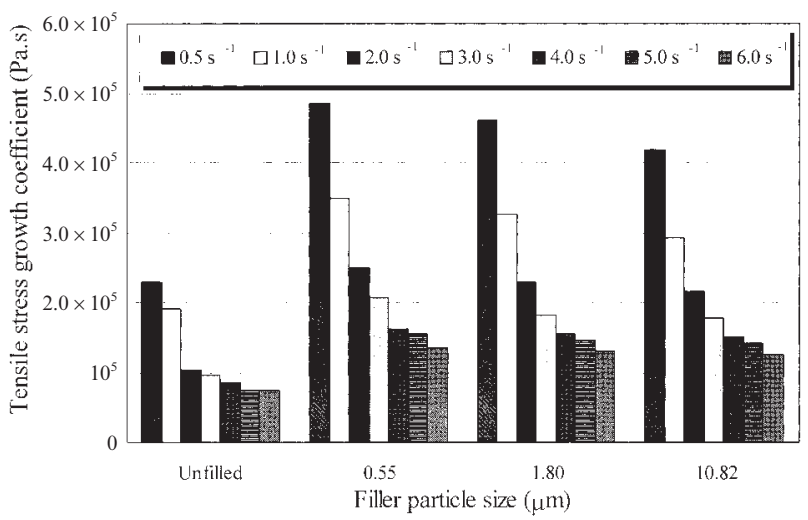

7 Data from Fig. 6 replotted as histogram to clarify effects of $\mathrm{CaCO}_{3}$ particle size on extensional stress growth data

determinant of extensional deformation of thermoplastics in the melt state, as a result of greater fillermatrix interaction. More precise comparisons of these effects should be made with reference to the MaronPierce model (equation (6)) since particle size also influences the maximum packing fraction parameter. Table 3 gives a summary of relevant information, including the actual (measured) melt state volume fractions $\phi_{\mathrm{f}}$, maximum packing fractions $\phi_{\max }$ inferred from oil absorption tests, and calculated relative viscosity functions $\left(\lambda_{\mathrm{f}} / \lambda_{0}\right)$. Reasonable agreement has been obtained and the results confirm that the highest viscosities are obtained with the ultrafine grade $\mathrm{CaCO}_{3}$. Overall, the predicted values underestimate the relative stress growth data that have been measured, especially for the additives of smallest particle size. This is thought to be related to imperfect filler dispersion in these compounds, resulting in immobilised polymer existing within the particle agglomerates, giving a higher effective volume fraction. ${ }^{19,44}$

\section{Extrusion blow moulding: rheology and processing}

Attempts have been made to examine some of the rheological data (from both shear flow and elongational deformation studies) in an applied context by using experiments on selected HDPE-B- $-\mathrm{CaCO}_{3}$ compounds processed on a commercial extrusion blow moulding unit; see 'Experimental: extrusion blow moulding'.

\section{Shear flow - output dynamics}

Mass output rate was measured directly from the extruder, over a range of rotational screw speeds, for a series of $\mathrm{CaCO}_{3}$ filled compounds based upon

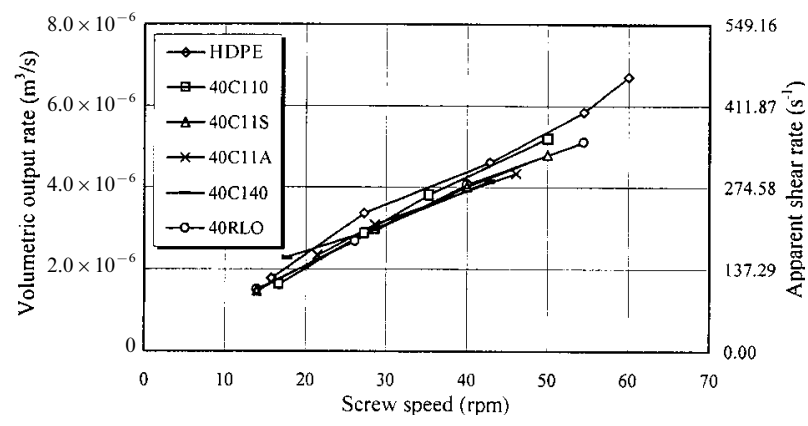

8 Extrusion blow moulding data: volumetric output and apparent shear rate $v$. rotational screw speed, for $\mathrm{CaCO}_{3}$ modified HDPE-B compounds processed at $190^{\circ} \mathrm{C}$

HDPE-B (Table 4). These data were then converted to volumetric output using melt density parameters that take account of the exact amounts of $\mathrm{CaCO}_{3}$ and fatty acid coatings included. The results are shown in Fig. 8, with shear rate data included on the ordinate, for reference purposes. There are no significant trends relating to the effects of $\mathrm{CaCO}_{3}$ content on volumetric output. Shear flow data have shown increases in viscosity due to filler incorporation, but to an extent that reduces at shear rates typical of commercial processes. ${ }^{35,43}$ Any such viscosity increase would influence shear flow dynamics both in the extruder metering section and the pressure flow through the die. ${ }^{23}$ Therefore the net, interactive effect of both screw speed and shear viscosity on volumetric output is very small and clearly cannot significantly differentiate between the compounds investigated without further expanding the processing window.

Mass output is enhanced significantly with filler incorporation due to melt density increases but ironically this effect is undesirable in the blow moulding industry, as a result of increased unit weight of containers. In view of the relatively consistent trends observed in Fig. 8, a constant screw speed of $31.5 \mathrm{rev} \min ^{-1}$ (corresponding to volumetric output rates of $\sim 3.5 \times 10^{6} \mathrm{~m}^{3} \mathrm{~s}^{-1}$ and an apparent shear rate of $240 \mathrm{~s}^{-1}$ ) was selected to make comparative results in subsequent sections of the blow moulding research.

\section{Melt elasticity - die swell}

The melt elasticity of selected compounds was characterised in terms of practical die swell measurements on extruded parisons, with respect to swelling about each principal axis (radial and circumferential). Overall, agreement was obtained with earlier, offline rheological analyses ${ }^{35,43}$ since the tendency for the

Table 3 Comparison between predicted and measured 'relative viscosity' ratios for $\mathrm{HDPE}-\mathrm{CaCO}$ compounds*

\begin{tabular}{lllll}
\hline & $\begin{array}{l}\text { Volume fraction } \\
\text { (melt state) }\end{array}$ & Maximum packing & \multicolumn{2}{l}{ Relative viscosity $\left(\lambda / \lambda_{0}\right)$} \\
\cline { 3 - 5 } Compound & $\phi_{\mathrm{f}}$ & $\phi_{\max }$ & Eqn (6) & $\dot{\varepsilon}=0.5 \mathrm{~s}^{-1}$ \\
\hline HDPE-B-RLO & 0.128 & 0.55 & 1.699 & 2.117 \\
HDPE-B-C110 & 0.121 & 0.66 & 1.499 & 2.003 \\
HDPE-B-C140 & 0.143 & 0.67 & 1.616 & 1.822 \\
\hline
\end{tabular}

* Predicted values obtained using equation (6), from the filler data in the table. Measured values are tensile stress growth coefficient data at $150^{\circ} \mathrm{C}$ at a Hencky strain of 1.5 (from Fig. 7 ). 

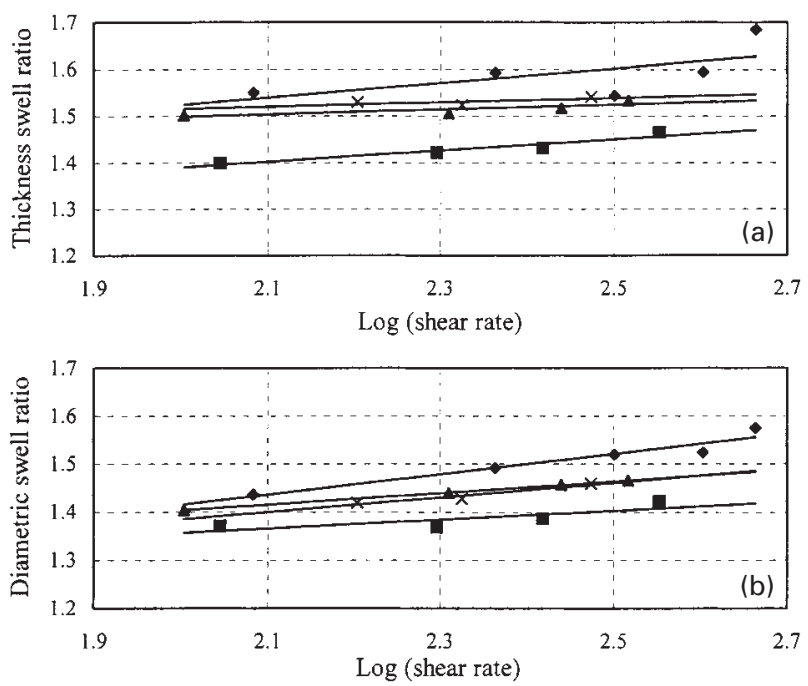

9 a Parison thickness and $b$ diametric swell ratio $v$. log (shear rate) for $\mathrm{HDPE}-\mathrm{B}-\mathrm{CaCO}_{3}$ compounds: ( ) HDPE; ( $)$ 40C110; ( $\triangle$ ) 40C11S; $(x)$ 40C11A

extruded parison to undergo swelling was reduced considerably when $\mathrm{CaCO}_{3}$ fillers were added to the compounds (Fig. 9). This is particularly so for the uncoated C110 filler, showing that melt elasticity and die swell are dependent upon polymer-filler interaction. Die swell also increases with shear rate, up to the point at which melt fracture is first apparent. These results can be interpreted in terms of shear modulus data derived from recoverable shear strain functions. ${ }^{5,21,41}$ When applied to shear flow data for the $\mathrm{HDPE}-\mathrm{CaCO}_{3}$ compounds, increases in shear modulus are always observed for compounds containing uncoated filler, but modulus is decreased when fatty acid coatings are incorporated, as a result of decreased filler-matrix interaction. ${ }^{43}$ The presence of filler coatings also appears to reduce the sensitivity of die swell to shear rate, to some extent.

Further die swell data on identical axes are shown in Fig. 10, which illustrates the influence of filler particle size. As in Fig. 9, radial (parison thickness) swell data are higher and distinguish more clearly between the compounds. Swelling appears to be higher for the $\mathrm{C} 140$ compound containing the largest particles, which has the lowest specific surface area (Table 2) and interaction with the polymer matrix. More extensive measurements over a wider processing range are clearly required to provide firm conclusions on the dependence of melt elasticity on the particle size of $\mathrm{CaCO}_{3}$ additives. Overall, die swell variation contributes to non-uniformity in parison dimensions

\begin{tabular}{ll} 
Table 4 & $\begin{array}{l}\text { Sample codes for } \\
\text { compounds used in extrusion blow } \\
\text { moulding }\end{array}$ \\
\hline
\end{tabular}

\begin{tabular}{ll}
\hline Compound & Sample code \\
\hline HDPE-B & HD55 \\
HDPE-B $+40 \%$ C110 & 40 C110 \\
HDPE-B $+40 \%$ C110S & 40C11S \\
HDPE-B + 40\% C110 (+10\% ATPE) & 40C11A \\
HDPE-B $+40 \%$ C140 & 40C140 \\
HDPE-B $+40 \%$ RLO & 40RLO \\
\hline
\end{tabular}
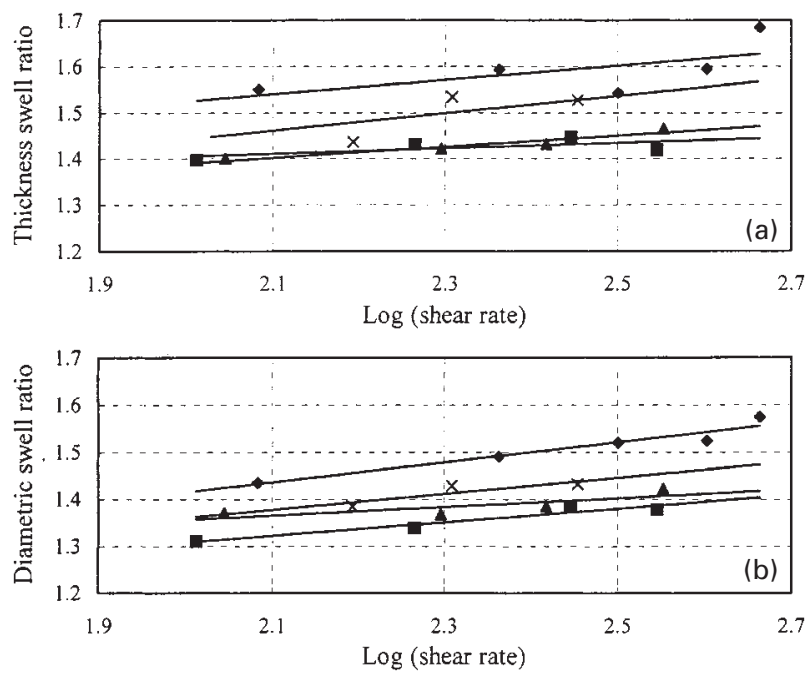

10 a Parison thickness and $b$ diametric swell ratio $v$. log (shear rate) for $\mathrm{HDPE}-\mathrm{B}-\mathrm{CaCO}_{3}$ compounds: ( ) HDPE; ( 1 ) 40RLO; ( $\triangle$ ) 40C110; $(x)$ 40C140

both directly and in conjunction with the effects of parison sag (see section 'Combined effects of die swell and parison sag', below). These lead to changes in container dimensions and geometry sensitive physical properties.

\section{Viscous elongational deformation - parison sag and filler volume fraction}

The most important practical relevance of elongational deformation and flow in extrusion blow moulding occurs in the sequential phases of parison sag (a low strain rate, predominantly viscous deformation) and inflation (a high strain rate phase initiated by hoop stress in the parison, determined by the blow pressure). These phenomena will be reviewed in this and in the subsequent section, using empirical analysis supported by some practical data.

Parison sag is an example of drawdown for which the vertical extension of the extrudate is driven by the force of gravity. While elongational viscosity is clearly an important material property, which determines the extent of extensional deformation, it should be noted that subsequent analysis is made more complex since viscosity is very sensitive to the effects of temperature and strain rate. Data presented above have demonstrated different levels of strain rate dependence, according to the volume fraction of particulate additives. In practical situations, strain rate cannot be considered constant, since the drawdown created by gravity during parison sag will induce extensional deformations (hence localised strain rates) which vary according to axial position. ${ }^{45}$ Extensional strain rate is zero in the leading element of the parison (at the free end) and assumes its maximum level at locations underneath the die, where the deforming stress is greatest. A spectrum of localised strain rates is therefore active and contributes to the overall degree of deformation in a complex manner. Maximum axial strain is often apparent in areas around the centre of the parison, due to the combined effects of tensile stress and application time. Temperature changes should also be considered, 


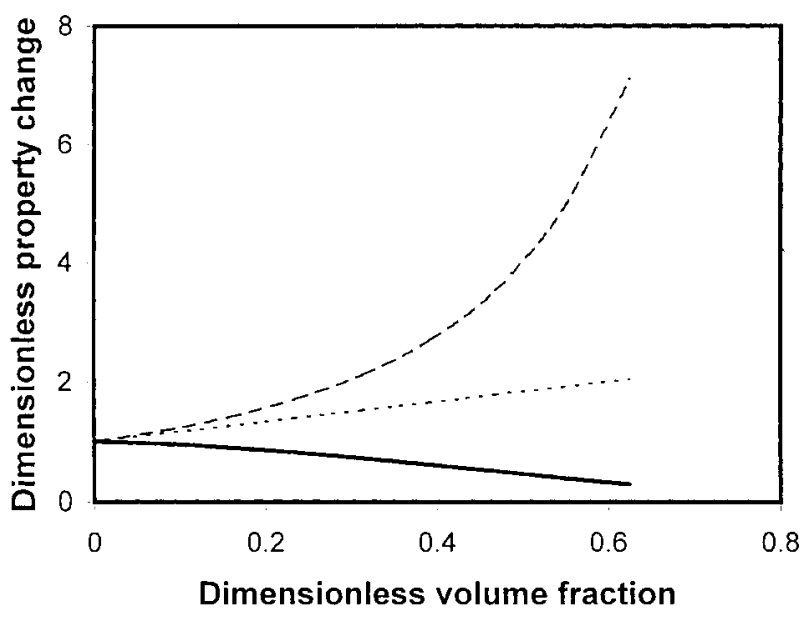

11 Changes in (-.......) density, (----) viscosity, and (-) density/viscosity in filled HDPE, expressed as function of $\mathrm{CaCO}_{3}$ volume fraction; density calculated from rule of mixtures and viscosity from equation (6)

especially for extended parison drop times, since heat will be lost by static convection to the surroundings. The magnitude of this non-isothermal effect is likely to be small in comparison with many other polymer processes however, since the surface heat transfer coefficients are low and in commercial practice, parison drop times are relatively short, especially in the production of thin wall containers.

An empirical expression which is often quoted to quantify the maximum parison extension $\Delta L$, relative to parison length $L$, and deformation time $t$ is given as follows ${ }^{41}$

$$
\Delta L=\rho_{\mathrm{m}} g t L^{2} / 2 \lambda(\dot{\varepsilon}, T)
$$

where parameters $\rho_{\mathrm{m}}$ and $\lambda(\dot{\varepsilon}, T)$ are the physical properties melt state density and elongational viscosity, respectively, and $g$ is the gravity constant. Each property is a function of filler content and these can be estimated, respectively, by a simple rule of mixtures and by using equation (6). Since elongational viscosity and melt density oppose each other with respect to parison deformation (equation (7)), a plot relating property changes to filler volume fraction is shown in Fig. 11. All parameters in the plot are dimensionless: viscosity and melt density are normalised relative to unfilled HDPE, while volume fraction data are normalised with respect to the maximum packing parameter $\phi_{\max }$ described in equation (6).

The dimensionless density/viscosity ratio can be assumed to be a driving force for parison sag and is shown to be a decreasing function of volume fraction. While this prediction would appear to be positive in terms of reducing sag and dimensional instability when particulate additives are incorporated in polymer melts, it should also be recognised that the plot cannot be considered to be unique; extensional viscosity is also a function of temperature and strain rate and sagging should not be considered in isolation from the interactive effects of die swell.

\section{Combined effects of die swell and parison sag}

There have been several approaches proposed to predict parison dimensions theoretically, in order to

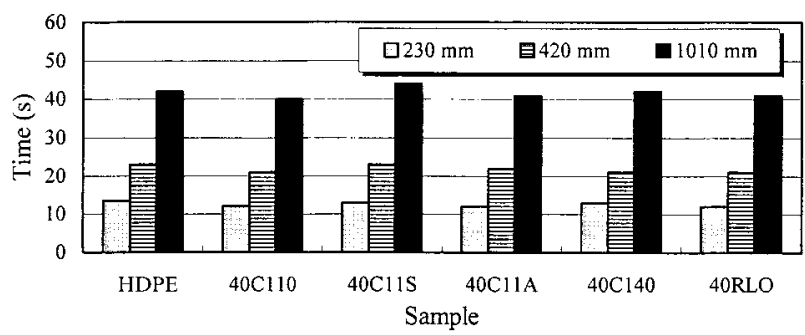

12 Extensional deformation data in extrusion blow moulding: parison drop times to reach specified vertical displacements

optimise part thickness distributions. ${ }^{45-48}$ However, this has proved to be difficult, as a result of the free surface deformation of complex geometries and the lack of an accurate constitutive equation to describe non-linear viscoelastic behaviour in the extrusion blow moulding process. ${ }^{45}$ Ideal extrusion behaviour would predict a linear relationship between parison length and time. In practice this does not occur, initially because of the effects of die swell and increasingly (but to a variable extent) as a result of drawdown and parison sag. ${ }^{45,49}$ The combined effects of swell and parison sagging must always therefore be considered, when predicting parison dimensions.

In this study, practical measurements of parison sagging were made by measuring the times taken to achieve a series of three pre-specified vertical displacements (Fig. 12). Despite having higher melt state densities, the $\mathrm{CaCO}_{3}$ filled compounds also have higher resistance to the effects of an axial tensile stress, so that for all compounds except that containing uncoated C110 filler, the times taken to achieve target parison length were marginally longer for the $\mathrm{CaCO}_{3}$ filled materials.

However, differences in practical data must also be interpreted by considering parison sag in combination with the simultaneous effects of die swell. Table 5 has been constructed on the basis of the differences in output dynamics (Fig. 8), thickness and diametric die swell (Fig. 9), and practical drop time data (Fig. 12), to enable distinctions to be made between the rheological behaviour of unfilled HDPE and compounds containing $40 \%$ of uncoated $(\mathrm{C} 110)$ and coated $(\mathrm{C} 110 \mathrm{~S}) \mathrm{CaCO}_{3}$. Because of its greater swell ratios, unfilled HDPE has a lower axial velocity (at a given volumetric output rate) and takes a longer period of time $t_{2}$ to reach a specific axial position. The difference between the calculated $t_{2}$ and experimental $t_{1}$ process times $\left(t_{2}-t_{1}\right)$ is related to the axial motion of the extrudate due to parison sagging. There is broad agreement between the observed sag times, predicted extensions due to sagging and the elongational viscosity data (Table 5), which confirms the qualitative validity of the approach. An additional point of relevance is to consider the effect of output dynnamics (row 2 in Table 5), since the high volumetric output recorded for unfilled HDPE-B results in some significantly different predictions for parison sag data.

The overall effect remains the same: $\mathrm{CaCO}_{3}$ filled compounds of higher viscosity and lower swell ratios are more resistant to the effects of gravity during the parison sag phase. It should be recognised however, that on the basis of the quoted deformations in 
Table 5, the calculated elongational strain rates for parison sagging were in the range $1.2 \times 10^{-3}$ (HDPE-C110S) to $4.6 \times 10^{-3} \mathrm{~s}^{-1}$ (unfilled HDPE), well below the experimental range over which viscosity and stress growth data were determined from the RER.

In summary, the respective influences of melt density and tensile stress growth data can be taken into account when predicting parison sagging behaviour of $\mathrm{HDPE}-\mathrm{CaCO}_{3}$ compounds in practical blow moulding and practical, 'single point' data have verified the semiquantitative predictions. Subsequent numerical approaches should include elastic swelling data and continuous, time dependent measurements of parison length. Greater accuracy can be achieved if strain rate sensitivity and non-isothermal effects are also taken into account.

\section{Parison inflation}

Parison deformation in response to internal air pressure during inflation is a high strain rate process and is driven principally by a tensile stress component $\sigma_{\mathrm{H}}$ acting in the hoop direction around the parison wall, which is related to inflation pressure $P$ and dimensions by

$$
\sigma=P D_{\mathrm{p}} / 2 H_{\mathrm{p}}
$$

Since the combined effects of swell and parison sag (see above) inevitably result in variable parison diameter $D_{\mathrm{p}}$ and thickness $H_{\mathrm{p}}$, localised variations in tensile stress are set up, which contribute further to the non-uniformity of wall thickness distributions and add complexity to computational analysis. The nonisothermal nature of the inflation phase should also be recognised, which results in a decreased inflation rate if viscosity increases due to heat loss. ${ }^{50}$ Some developments in research aimed at modelling parison inflation have been quoted by Diraddo and GarciaRejon, ${ }^{45}$ and more recently, progress towards a software based, free surface process analysis for blow moulding has been reported. ${ }^{51}$

For the present study focused upon rheological variations in HDPE compounds modified by mineral fillers, a series of bottle thickness data has been obtained (Fig. 13). The standard deviations quoted on the histogram indicate the levels of thickness variability along both the axial and circumferential positions quoted.

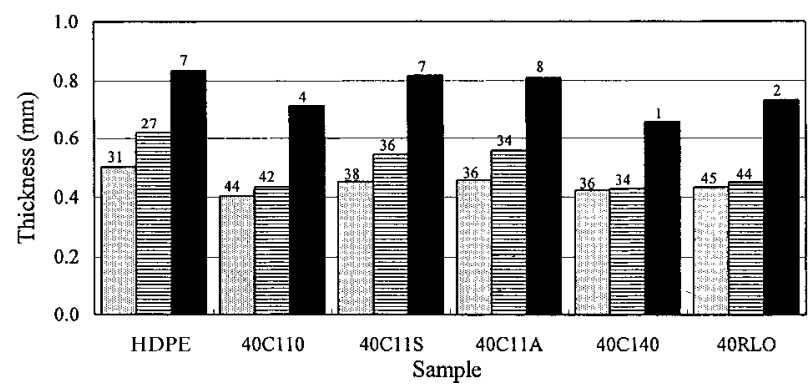

13 Average blow moulded container thickness data in axial and circumferential directions for HDPE modified by range of $\mathrm{CaCO}_{3}$ fillers: ( $\square$ ) thickness around bottle near neck; (員) thickness around bottle near base; ( 1 ) thickness along length of bottle; standard deviation shown in numerals on histogram (\%)

There is clear correlation between the average axial thicknesses and the parison swelling data presented above; the unfilled HDPE polymer has the largest overall average thickness, as a result of the high principal swelling ratios (Figs. 9 and 10). Moreover, compounds containing coated $\mathrm{CaCO}_{3}$ have greater average thicknesses than the HDPE-C110 (uncoated) compound, for the same reason. In addition however, axial thickness variability in HDPE is higher than in the majority of the other materials, because of the combined effects of die swell and parison sag discussed above.

The predominance of parison sag has determined that average bottle thicknesses are consistently higher at locations close to the base, rather than underneath the neck (Fig. 13). Elongational viscosity or stress growth parameters, which decrease with increasing strain rate, (Fig. 2) might be expected to create high levels of thickness variation following inflation, especially in instances where the initial parison thickness is relatively low (e.g. for filled compounds). This is shown to some extent by the magnitude of variation on the circumferential thickness distributions.

Two additional effects are important in this respect; melt state (tensile) modulus characterises the elastic component of deformation and has been shown to increase with increasing stress, ${ }^{35}$ an observation which contributes to dimensional stability. However, once the first deforming elements of the parison make

Table 5 Extrusion blow moulding data for $\mathrm{HDPE}-\mathrm{CaCO}_{3}$ compounds: comparisons of die swell, parison sagging, and viscosity data*

\begin{tabular}{|c|c|c|c|c|c|c|c|c|c|c|}
\hline Compound & $\begin{array}{l}\text { Melt } \\
\text { density } \rho_{\mathrm{m}}, \\
\mathrm{kg} \mathrm{m}^{-3}\end{array}$ & $\begin{array}{l}\text { Swell ratio } \\
\text { (thickness) } B_{\mathrm{H}}\end{array}$ & $\begin{array}{l}\text { Swell ratio } \\
\text { (diameter) } \\
B_{\mathrm{D}}\end{array}$ & $\begin{array}{l}\text { Parison } \\
\text { area, } A_{\mathrm{p}} \\
\times 10^{-6} \mathrm{~m}^{2}\end{array}$ & $\begin{array}{l}\text { Axial } \\
\text { velocity } V_{Z,} \\
\mathrm{~m} \mathrm{~s}^{-1}\end{array}$ & $\begin{array}{l}\text { Time } t_{2} \\
\text { (calc.), } \\
\mathrm{s}\end{array}$ & $\begin{array}{l}\text { Time } t_{1} \\
\text { (exp.), } \\
\mathrm{s}\end{array}$ & $\begin{array}{l}\text { Parison } \\
\text { sag time } \\
\left(t_{2}-t_{1}\right) \\
\mathrm{s}\end{array}$ & $\begin{array}{l}\text { Tensile } \\
\text { viscosity } \lambda \text {, } \\
\operatorname{kPa~s}^{-1}\end{array}$ & $\begin{array}{l}\text { Axial } \\
\text { extension } \\
\Delta L, \\
\mathrm{~mm}\end{array}$ \\
\hline HDPE-B & 750 & 1.59 & $1 \cdot 50$ & $166 \cdot 9$ & 0.0200 & $50 \cdot 6$ & $42 \cdot 3$ & $8 \cdot 3$ & 616 & 164 \\
\hline HDPE† & 750 & 1.59 & $1 \cdot 50$ & $166 \cdot 9$ & 0.0223 & $45 \cdot 3$ & $42 \cdot 3$ & $3 \cdot 0$ & 616 & 67 \\
\hline HDPE/C110 & 987 & $1 \cdot 43$ & $1 \cdot 39$ & $139 \cdot 1$ & 0.0239 & $42 \cdot 2$ & $40 \cdot 1$ & $2 \cdot 1$ & 990 & 52 \\
\hline HDPE/C110S & 1008 & $1 \cdot 52$ & $1 \cdot 45$ & $154 \cdot 1$ & 0.0216 & $46 \cdot 7$ & $44 \cdot 4$ & $2 \cdot 3$ & 886 & 51 \\
\hline
\end{tabular}

* HDPE and $\mathrm{CaCO}_{3}$ filler data; see Tables 1 and $2 ; t_{1}$ parison sag data, experimental drop time to a displacement of 1010 mm (from Fig. 12); $t_{2}$ parison sag data, calculated drop time, based upon volumetric output (Fig. 8) and die swell (Fig. 9); $t_{2}-t_{1}$ reduction in practical drop time, due to the influence of viscous parison sag; $\Delta L$ degree of parison sag (predicted increase in axial length), over the experimental drop time; $\lambda$ comparative extensional viscosity data are given in the penultimate column, for a strain rate of $0.1 \mathrm{~s}^{-1}$.

t HDPE, HDPE-B data, recalculated to take account of increased volumetric output for this grade (see Fig. 8). 
contact with the long face of an elliptical mould, thermal contact is made and the unconstrained elements would be expected to deform preferentially (and at a higher localised strain rate), thereby producing non-uniform dimensions around the container perimeter. Since the $\mathrm{CaCO}_{3}$ filled compounds lose heat more rapidly, this non-uniformity would be especially evident.

In these experiments, air flowrates into the mould were not measured accurately, but if an inflation time of $0.2 \mathrm{~s}$ is assumed, an extensional strain rate of $6.4 \mathrm{~s}^{-1}$ can be calculated, which lies close to the maximum strain rate in the rheological analysis (Figs. 2, 6, and 7). A blow pressure of $0.070 \mathrm{MPa}(10 \mathrm{psi})$ equates to a developed hoop stress of $0.464 \mathrm{MPa}$ in the unfilled HDPE parisons (using equation (8), with data from Table 5), so that a transient state extensional viscosity of $7 \cdot 2 \times 10^{4} \mathrm{~N} \mathrm{~s} \mathrm{~m}^{-2}$ is calculated, which lies in close agreement with the extensional flow (stress growth) data in Figs. 2, 4, and 6.

The correlations between the extensional flow data and practical blow moulding measurements indicate the potential use of the rheological characterisations in polymer process simulation techniques. More accurate predictions based upon these data in computational analysis are feasible, for which the influence of material properties (volume fraction, particle size, filler coatings) and process variables (temperature, swelling ratios, inflation pressure) could be carefully optimised.

\section{Extrusion blow moulding - physical properties}

Analysis of dimensions and mechanical properties was subsequently carried out on blow moulded containers. Since these properties are interdependent, and influenced by processing as well as by the direct compound formulation, an overall 'cause and effect' summary was difficult to ascertain with accuracy. Instead, a number of additional characterisation techniques were implemented in order to interpret the differences in properties that were observed.

\section{Uniaxial tensile properties}

One of the advantages of using particulate additives in thermoplastics is mechanical property enhancement. However, the mechanisms of reinforcement dictate that in many circumstances, only certain properties can be improved and therefore the potential advantages obtained by using particulate, mineral based fillers remain applications specific, to some extent. For example, as long as a modest degree of filler-matrix adhesion can be established, rigid particulate additives are able to enhance low strain modulus almost universally, in many thermoplastic compounds. $^{2-5,12}$ Other mechanical properties (yield stress, energy absorption, toughness) depend upon many additional, often interactive effects and cannot yet be predicted with any accuracy by simulation. In particular, for ductile matrix composites based upon thermoplastics such as HDPE, retention of ductile mode failure is often essential to the success of the approach, since the polymer is often specified for applications that require high resistance to the effects
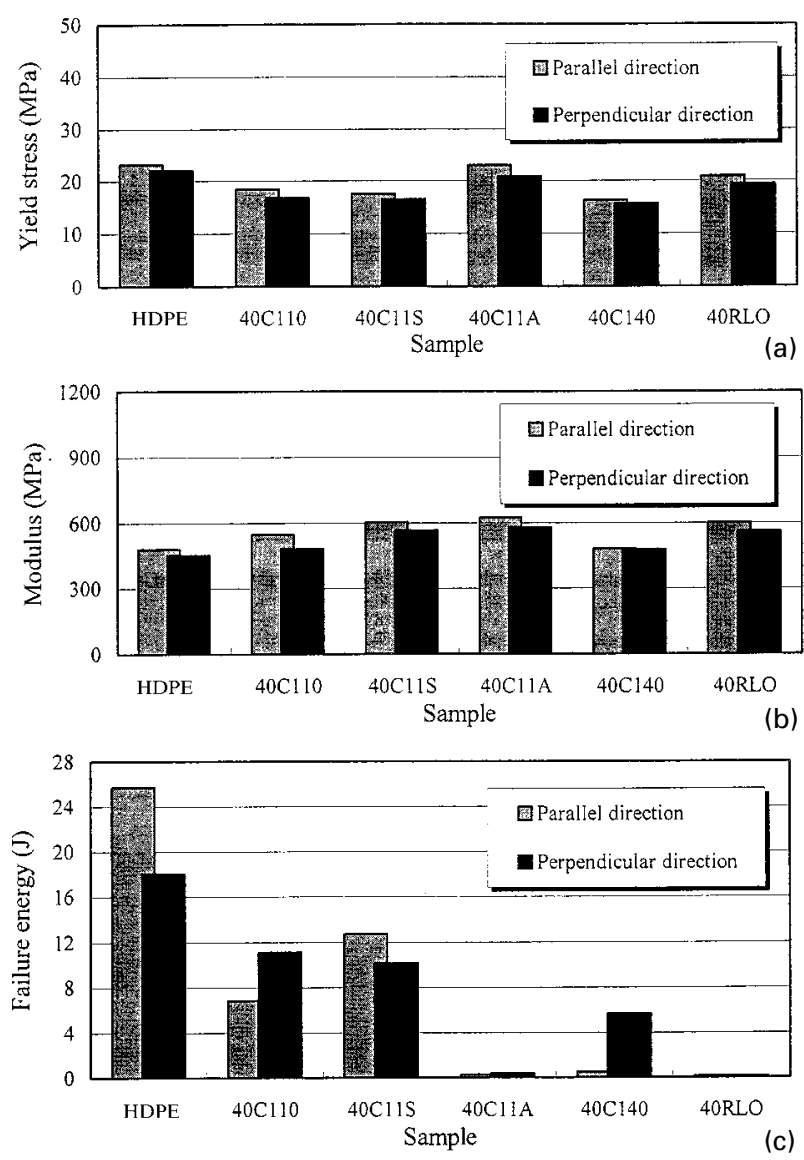

14 Mechanical properties of blow moulded HDPE$\mathrm{B}-\mathrm{CaCO}_{3}$ containers in tension at ambient temperature: $a$ yield stress; $b$ modulus; $c$ failure energy

of loading conditions, which might otherwise promote brittle mode fracture.

A summary of some of the experimental data for uniaxial tensile tests is given in Fig. 14. Crosshead speed was $20 \mathrm{~mm} \mathrm{~min}^{-1}$, which corresponds to a nominal tensile strain rate of $0 \cdot 016 \mathrm{~s}^{-1}$. Overall, while all compounds exhibited a clear yield point, a wide spectrum of post-yield mechanical responses was observed, depending upon the compound constituents and their influence on processing. Generally, yield stress decreased with filler incorporation, relative to unfilled HDPE-B, consistent with other literature, for example, Ref. 5. Compounds that gave similar yield stress parameters to HDPE included those containing filler coated with ATPE, where greater physical interaction between the matrix and the long aliphatic chains of the low molar mass polymeric coating occurs. Similar results using ATPE coatings with magnesium hydroxide fillers have also been derived in parallel studies. ${ }^{15}$ Therefore ATPE acts as a physical coupling agent, as well as a filler coating. The surface polarity of $\mathrm{CaCO}_{3}$ is decreased when fatty acid coatings are introduced and although this improves filler wettability (by the polymer), it reduces filler-matrix interaction (or interfacial adhesion) in comparison with systems modified by uncoated filler. ${ }^{52}$ In addition, particle size effects are important and the higher specific surface area of the ultrafine 


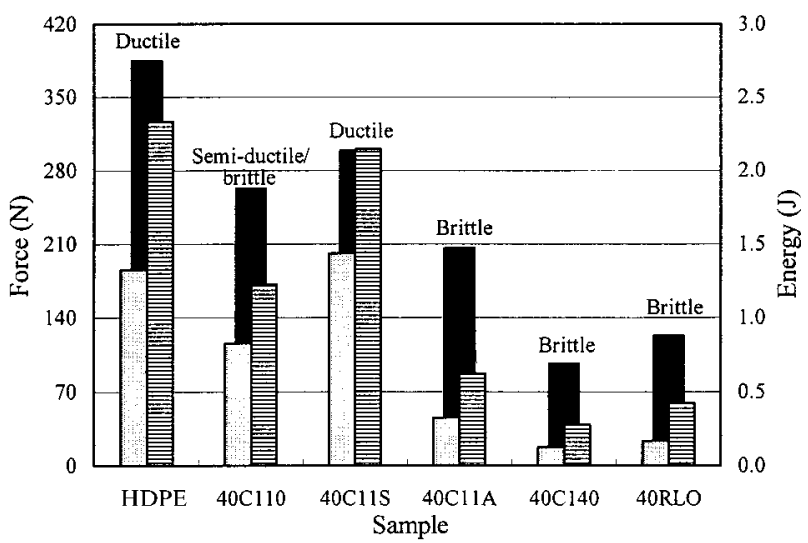

15 Instrumented impact data for blow moulded HDPE-B- $\mathrm{CaCO}_{3}$ containers under impact loading at $-40^{\circ} \mathrm{C}$ : ( $\square$ ) peak force; ( $\square$ ) peak energy; (員) failure energy

filler (40RLO, in Fig. 14a) will also contribute to the same effect, albeit by a different mechanism.

Modulus was increased to some extent for all HDPE compounds modified by $\mathrm{CaCO}_{3}$ (Fig. 14b). Most notably, a clear trend relating to particle size exists for the uncoated fillers, with the uncoated finer grade materials promoting modulus enhancement to the greatest extent, due to the enhanced adhesion of high specific area additives. Nominal strain at the yield point was $6-8 \%$ in all cases. Consistent with the yield stress data, ATPE coating also enhances the low strain modulus of $\mathrm{HDPE}-\mathrm{CaCO}_{3}$ composites. Energy absorption data are strongly dependent on the ability of the material to undergo stable necking and cold drawing to high strain, following the initial yield process. This parameter is able to differentiate quite clearly between the mechanical performance of some compounds. All filled specimens showed reduced energy absorption (Fig. 14c), as a result of ultimate failure at a lower tensile strain. Filler dispersion is an important factor in this respect and has influenced the energy absorption data for the ultrafine RLO grade (see also section on 'Filler dispersion'). Particle agglomerates (in the range $1-5 \mu \mathrm{m}$ ) detract from the ability of the filled HDPE to undergo macroscopic scale cold drawing as a result of cohesive intraparticle failure, which creates microscopic defects, concentrates stress, and is able to initiate premature failure immediately following yielding.

Properties were measured both parallel and perpendicular to the main axis of the containers. A number of specimens showed some apparent mechanical anisotropy (Fig. 14) so that birefringence measurements were made on selected specimens in order to assess the contribution of any molecular orientation (see section 'Other structural phenomena'). Anisotropic effects cannot originate from preferred filler particle orientation, since the additives have a pseudospherical morphology.

\section{Multiaxial impact properties}

Instrumented falling weight impact tests were carried out at $-40^{\circ} \mathrm{C}$ to assess both qualitative failure modes and quantitative impact energy absorption data. Specimens were machined directly from the walls of blow moulded containers and are therefore subject to

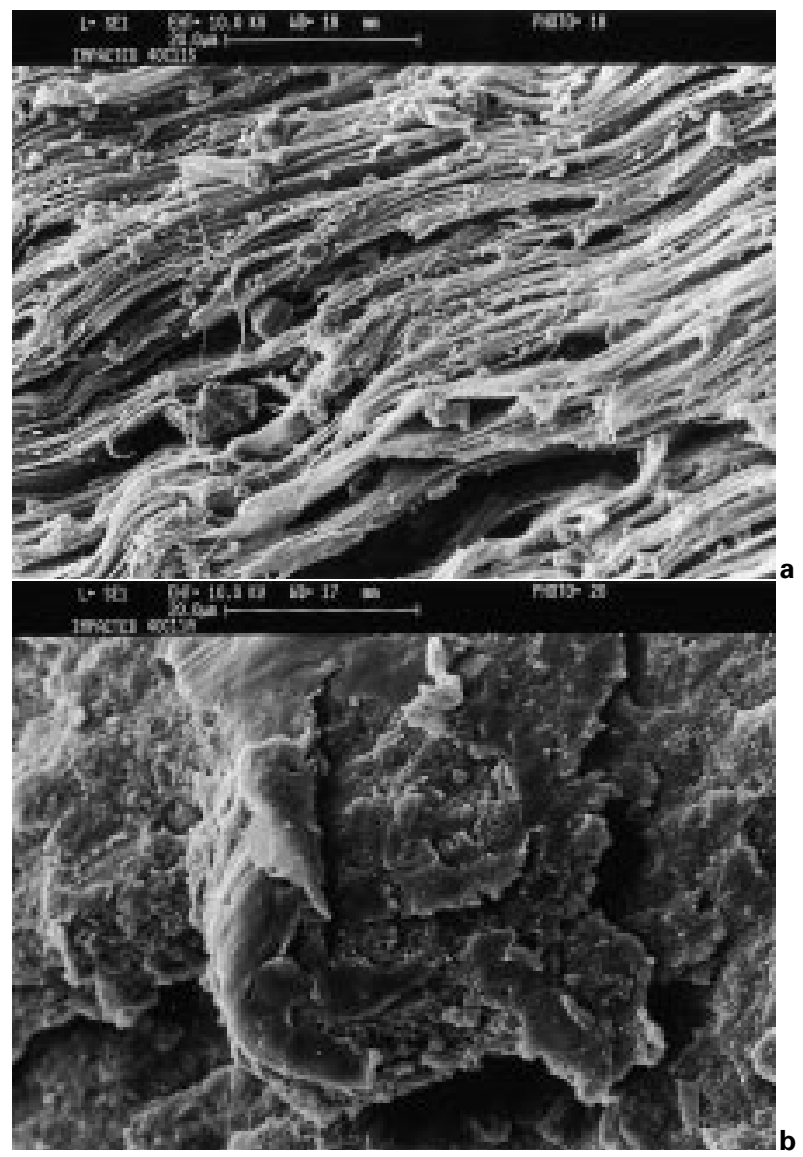

16 Scanning electron micrographs of HDPE$\mathrm{B}-\mathrm{CaCO}_{3}$ fracture surfaces from instrumented impact tests: a $40 \%$ C110S filler, ductile mode failure; $b \quad 40 \% \quad 110+$ ATPE coating, brittle fracture

$\times 1050$

dimensional fluctuations as a result of the different rheological responses, which have been discussed above. The results in this section (maximum force and failure energy) are therefore geometry dependent. If ductile mode failure occurs, the peak force data indicate yield stress values determined under high strain rate, low temperature conditions (Fig. 15). However, mixed mode failures were observed and in examples having predominantly brittle failures, maximum force is related to a critical degree of stress intensity and cannot be compared directly with equivalent data from specimens that failed in a ductile manner.

Consequently, the most meaningful parameter is the ultimate failure energy in Fig. 15, data from which correlate with the energy absorption results from the low strain rate tests (Fig. 14c). Compounds that suffered brittle mode failure under impact loading include the two specific examples in which increased yield stress was apparent (ATPE coated C110 and C140 fillers), an effect which is exaggerated further under low temperature, high strain rate loading. The extent to which yielding is able to occur is clearly the important factor in achieving high levels of impact resistance in these compounds. Electron micrographs shown in Fig. 16 (magnification $\times 1050$ ) demonstrate first how highly oriented microfibrils of cold drawn polyethylene are formed and dominate the rupture 
surface in ductile mode failure (Fig. 16a). A large number of loose filler particles are evident around the highly strained matrix, consistent with a relatively low level of adhesion existing between the non-polar polymer and the coated filler particles. In contrast, Fig. $16 b$ shows a relatively featureless brittle fracture morphology, characteristic of rapid crack growth in the compound containing the same filler (C110), coated with high molar mass ATPE. Notably, there is little or no evidence of detached $\mathrm{CaCO}_{3}$ particles, demonstrating a more cohesive failure mechanism due in part to the enhanced interaction between HDPE and the coated filler.

Most significantly, the ductile mode failure mechanism was retained in HDPE-B compounds containing C110S grade $\mathrm{CaCO}_{3}$. Similar enhancements in impact toughness in polyalkenes have also been attributed to the presence of organic coatings. ${ }^{53,54}$ It is suggested that under the processing regime adopted, the particle size of the C110S grade is close to an optimum level. It is neither large enough to induce excessive stress concentration and crack initiation, ${ }^{55}$ nor is it small enough to have created specific difficulties in particle dispersion under the compounding conditions adopted. These respective factors have each been shown to be a potential source of embrittlement in other $\mathrm{HDPE}-\mathrm{CaCO}_{3}$ compounds. This result is highly significant, demonstrating that by optimising particle size, filler coating, dispersibility, and processing, it is feasible to obtain enhanced modulus in $\mathrm{CaCO}_{3}$ modified HDPE while retaining ductile mode impact failure at $-40^{\circ} \mathrm{C}$.

\section{Filler dispersion}

Previous work has shown how filler dispersion can be described by a specific energy parameter derived from online measurements at the compounding stage, which can be correlated to compound formulation by experimentally derived measurement. ${ }^{15,35,43}$ In this research, similar levels of particle dispersion were achieved in most compounds, as exemplified by the electron micrographs of acid etched surfaces in Fig. $17 a$ and $b$. This high degree of dispersive mixing is achieved using lower levels of power and input energy, when coated fillers are used. ${ }^{43}$ Figure $17 c$ is a micrograph of HDPE compound containing uncoated, ultrafine RLO filler, shown at a magnification high enough to demonstrate the existence of surface defects of up to $3 \mu \mathrm{m}$ in size. Some of these features are thought to represent areas occupied by particle agglomerates, prior to etching. Other locations in the micrograph exhibit exceptionally high levels of dispersion. This result confirms the existence of some particle agglomerates in compounds containing uncoated RLO filler, which are thought to have contributed to the brittle mode failure and low energy absorption characteristics of the HDPE compounds. Fine grade fillers offer great potential for enhancement of impact properties and toughness in polyalkenes, but clearly the compounding conditions and choice of surface coatings need to be optimised to avoid undesirable effects due to imperfect dispersion.

\section{Other structural phenomena}

The above results have demonstrated the complex nature of mechanical property prediction in particle

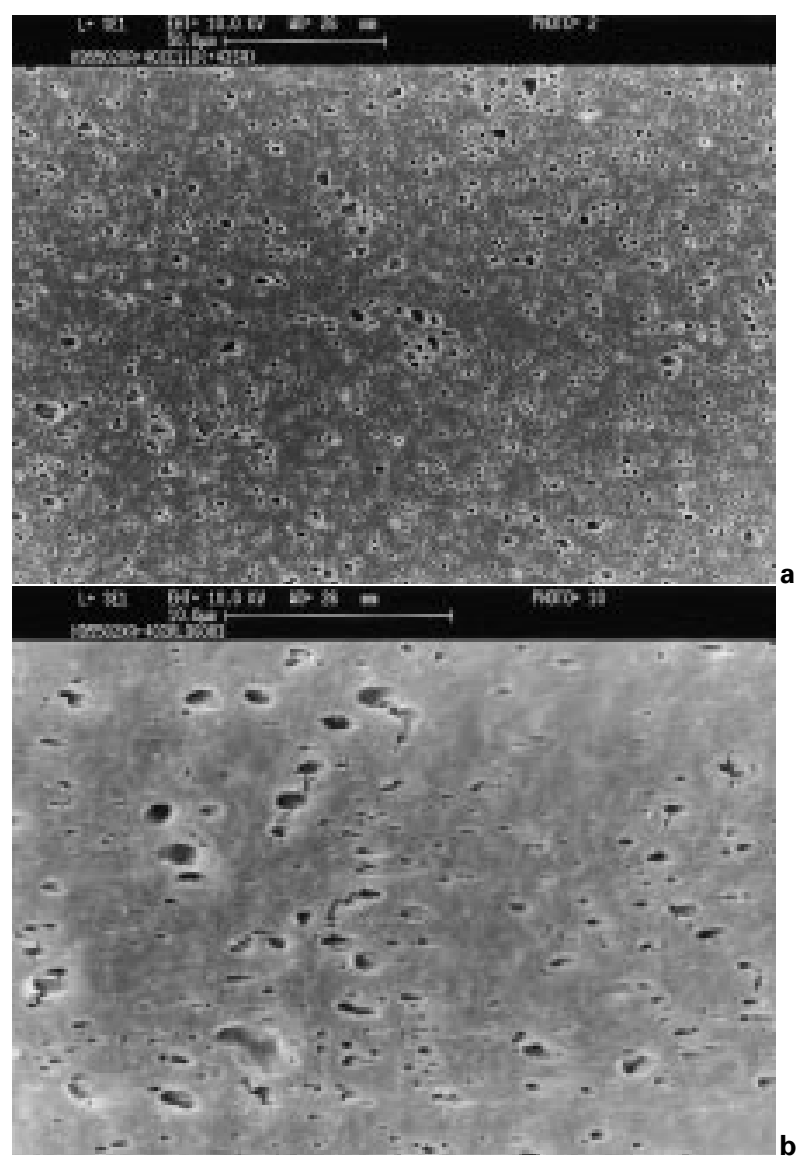

17 Scanning electron micrographs of HDPE$\mathrm{B}-\mathrm{CaCO}_{3}$ specimen surfaces which have been microtomed and etched with $\mathrm{HCl}$ to reveal filled polymer morphology: a HDPE-B $+40 \%$ C110 ( $4 \%$ stearic acid coating); $\times 350 ; b$ HDPEB $+40 \%$ RLO (uncoated); $\times 2450$

modified polyethylene composites, due to the large number of factors that hold some degree of influence. In order to compile more complete interpretations of the measured property changes, some additional studies were made to characterise structure related phenomena that are also induced by formulation and processing differences.

Blow moulding involves high elongational strains developed at high deformation rates during the inflation phase. In view of the apparent anisotropic effects observed from tensile tests (Fig. 14) some birefringence measurements were made to assess the direction and magnitude of molecular orientation in the containers. Principal birefringences were 0.79 and $0.85 \times 10^{-3}$ (parallel and perpendicular respectively, to the main container axis), which suggests that there is no preferred molecular orientation in the plane of the container wall. Apparent differences in mechanical properties are more likely to be related to dimensional changes, notably thickness variations in the containers.

Particulate additives are known to have an influence on the crystallisation kinetics and morphology of semicrystalline polymers. Extensive studies of both as compounded and blow moulded $\mathrm{HDPE}-\mathrm{CaCO}_{3}$ were undertaken using DTA, the results of which will be reported separately. In summary, the results 
showed that none of the thermal properties measured by DTA was significantly changed by incorporation of fillers or fatty acid coatings. A small increase in recrystallisation temperature was detected for all filled samples during the cooling phase, suggesting a secondary nucleation effect. This was relatively small however and did not change the overall developed crystallinity in the polyethylene phase. ${ }^{35}$ Overall therefore, it is suggested that differences in molecular orientation and polymer crystallinity had little or no direct influence on the measured physical properties of the blow moulded containers.

\section{CONCLUSIONS}

The extensional flow data obtained from the Rutherford elongational rheometer (RER) have been captured at high strain rates to a high degree of accuracy, despite the very short test timescales involved. Some clear differences between the deformation and rupture behaviour of high density polyethylene (HDPE) $-\mathrm{CaCO}_{3}$ composites tested in the melt state have emerged and the data are available for subsequent numerical analysis in process simulation.

1. Transient state tensile stress growth data and the viscoelastic transition associated with strain hardening are sensitive to HDPE molecular weight and the RER data have confirmed that HDPE is a tension thinning polymer melt. Increased polymer-particle interaction contributes to greater deformation resistance when HDPE polymers are modified by $\mathrm{CaCO}_{3}$ fillers, although the overall response pattern and strain rate sensitivity (for a given set of experimental conditions) is similar.

2. Extensional viscosity is more sensitive to the volume fraction of $\mathrm{CaCO}_{3}$ at low elongational strain rates and can be modelled by a form of the MaronPierce relationship, if the maximum packing fraction can be determined accurately. Morphology controlled compound viscosity is therefore feasible. Fine particle size fillers increase stress growth data owing to their higher specific surface area and the corresponding influence on maximum packing fraction.

3. The influence of filler coatings is not as marked as strain rate and volume fraction effects. In free surface flows, for which external lubrication effects are irrelevant, incorporation of coatings leads to reductions in viscosity only when the concentration of calcium stearate salt (a byproduct of the coating reaction involving stearic acid) is sufficient to induce internal lubrication.

4. Under the constant strain rate conditions adopted at $150^{\circ} \mathrm{C}$, only the HDPE polymers of lowest molar mass (typically $100000 \mathrm{~g} \mathrm{~mol}^{-1}$ ) exhibited tensile melt rupture by localised viscous necking, at Hencky strains below the experimental maximum. Addition of $\mathrm{CaCO}_{3}$ modifies extensional stress growth behaviour so that the location of rupture occurs at a higher true stress, but at a reduced Hencky strain; these parameters are also deformation rate dependent.

Experimental blow moulding studies were used to investigate the application of the rheological data obtained, in terms of processing behaviour and related effects on structure and mechanical properties of $\mathrm{CaCO}_{3}$ modified HDPE containers.
1. While extrusion dynamics of HDPE melts are little affected by $\mathrm{CaCO}_{3}$, practical die swell is reduced significantly by filler incorporation, an effect that has been interpreted in terms of the dependence of shear modulus on filler-matrix interaction. Swelling is also modified by particle size and by fatty acid coatings.

2. Extensional viscosity and melt density are both influenced by inorganic fillers and each property contributes to parison sagging. When considered in combination with die swell, practicle parison deformations correlate with the extensional flow properties that have been characterised by rheological analysis. Container thickness distributions measured following parison inflation also depend upon dimensional variations created by differential swelling and parison deformation phases of the process.

3. $\mathrm{CaCO}_{3}$ incorporation increases low strain modulus in HDPE. Modulus enhancement and retention of yield stress occurs when fine particle size fillers are specified and when using acid terminated polyethylene coating, which acts as a physical coupling agent as well as a dispersion promoter.

4. Energy absorption properties are generally reduced by filler incorporation. However, ductile mode impact failure in filled HDPE composites can be retained if particle size is optimised and if dispersive mixing at the compounding stage is sufficiently intensive to destroy particle agglomerates. High strain rate deformations in blow moulding have little influence on crystallinity development and in plane orientation in filled HDPE.

\section{ACKNOWLEDGEMENTS}

The authors would like to acknowledge the contributions made by $\mathrm{Mr}$ N. A. Miller, Loughborough University, to the elongational rheometry and by Dr D. A. Hemsley, Polymer Microscopy \& Services, to the birefringence studies. The support of ECC International and BP Chemicals, for their technical input and supply of materials, is also acknowledged.

\section{REFERENCES}

1. W. HOHENBERGER: Kunststoffe, 1996, 80, (7), 18.

2. A. D. KUPFER and R. RozetT: Proc. Ann. Technical Conf., USA, 1984, Society of Plastics Engineers, p. 191.

3. T. M. MALIK, P. J. CARREAU, M. GRMELA, and A. DUFRESNE: Polym. Compos., 1988, 9, (6), 412.

4. H. P. SCHREIBER, J. M. VIAU, A. FETOUI, and Z. DENG: Polym. Eng. Sci., 1990, 30, (5), 263.

5. S. N. MAiti and R. JeYAKumar: J. Polym. Mater., 1990, 7, (1), 29.

6. J. KUBÁT, J. A. MÅNSON, and M. RIGDAHL: 'Polymer processing and properties', (ed. G. Astarita and L. Nicolais); 1984, New York, Plenum Press.

7. C. D. han, H. L. LuO, and J. MiJovic: Proc. Ann. Technical Conf., USA, 1982, Society of Plastics Engineers, p. 82.

8. P. K. FREAKLEY and C. SIRISINHA: Kaut. Gummi. Kunst., 1997, 50, 608.

9. P. M. McGENITY, J. J. HOOPER, C. D. PAYNTER, A. M. RILEY, C. NUtBeem, N. J. Elton, and J. M. ADAMS: Polymer, 1992, 33, 5215.

10. Y. Suetsugu: Intl. Polym. Process., 1990, 5, (3), 184.

11. X. XU and X. GONG: Chinese J. Polym. Sci., 1991, 9, (2), 108.

12. R. ROTHON: 'Particulate-filled polymer composites'; 1995, London, Longman. 
13. E. PAPIRER, J. SCHUltz, and C. TURChI: Eur. Polym. J., 1984, 20, (12), 1155.

14. J. JANCAR: J. Mater. Sci., 1989, 24, 3947.

15. C. L. RAYMOND: 'Coatings for magnesium hydroxide fillers in polyethylene compounds', PhD thesis, Loughborough University, UK, 1997.

16. K. EISE: 'Polymer additives', (ed. J. E. Kresta); 1984, New York, Plenum Press.

17. C. T. HILL: Proc. Engineering Properties and Structure Division 'Additives', Divtec Hudson, OH, USA, 1975, Society of Plastics Engineers.

18. L. K. GRIGOR'EVA, M. L. KERBER, I. O. STAL'NOVA, and T. v. MaKsimova: Int. Polym. Sci. Tech., 1988, 15, (6), 75.

19. C. SIRISINHA: 'Mechanisms of extrudate swell and melt fracture in SBR compounds', PhD thesis, Loughborough University, UK, 1996.

20. P. R. HORNSBY and A. MTHUPHA: J. Mater. Sci., 1994, 29, 5293.

21. y. Suetsugu and J. L. White: J. Appl. Polym. Sci., 1983, 28, 1481.

22. J. M. DEALY: 'Rheometers for molten plastics'; 1982, New York, Van Nostrand.

23. A. W. BIRLEY, B. HAWORTH, and J. BATCHELOR: 'Physics of plastics: processing, properties and materials engineering'; 1992, Munich, Hanser.

24. F. N. COGSWELl: Trans. Soc. Rheol., 1972, 16, (3), 383.

25. H. MÜNSTEDT: J. Rheol., 1979, 23, 421.

26. D. G. SMOKER: 'A study of the extensional flow behaviour of low density polyethylene', $\mathrm{PhD}$ thesis, Loughborough University, UK, 1984.

27. F. H. AXTELL: 'A study of the flow properties and processability of thermoplastic polyesters', $\mathrm{PhD}$ thesis, Loughborough University, UK, 1987.

28. F. H. AXTELl and B. HAWORTH: Plast. Rubber Compos. Process. Appl., 1994, 22, (3), 127.

29. B. HaWORTH, N. L. THOMAS, and L. ChUA: Plast. Rubber Compos. Process. Appl., 1994, 22, (3), 159.

30. A. T. MUtel and M. R. Kamal: Proc. Ann. Technical Conf., USA, 1986, Society of Plastics Engineers, p. 679.

31. F. H. AXTell and B. HAWORTH: Polym. Test., 1990, $9,53$.

32. B. HAWORTH and S. JUMPA: Polym. Test., to be published.

33. J. MEISSNER: Polym. Eng. Sci., 1987, 27, (8), 537-546.
34. J. M. DEALY: J. Rheol., 1995, 39, (1), 253.

35. S. JUMPA: 'Elongational rheometry and processing of filled polyethylene melts', $\mathrm{PhD}$ thesis, Loughborough University, UK, 1998.

36. M. RIDES, C. ALLEN, and S. CHAKRAVORTY: Proc. Int. Conf. 'PPS-15', S'Hertogenbosch, The Netherlands, 1999, Polymer Processing Society, Paper 224.

37. Y. IDE and J. L. WHITE: J. Appl. Polym. Sci., 1978, 22, 1061.

38. H. MUNSTEDT and H. M. LAUN: Rheol. Acta, 1981, 20, 211.

39. W. Minoshima, J. L. White, and J. E. SPRUiell: Polym. Eng. Sci., 1980, 20, (17), 1166.

40. A. Y. MALKIN and C. J. S. PETRIE: J. Rheol., 1997, 41, (1), 1.

41. F. N. COGSWELL: 'Polymer melt rheology', 2nd edn; 1994, Cambridge, Woodhead.

42. Y. BOMAL and P. GODARD: Polym. Eng. Sci., 1996, 36, (2), 237.

43. B. HAWORTH, S. JUMPA, and N. A. MILLER: Proc. Int. Conf. 'PPS-15', S'Hertogenbosch, The Netherlands, 1999, Polymer Processing Society, Paper 132.

44. C. SIRISINHA and P. K. FREAKLEY: Plast. Rubber. Compos. Process. Appl., 1997, 26, (3), 113.

45. R. W. DiRADDO and A. Garcia-ReJon: Polym. Eng. Sci., 1992, 32, (19), 1401.

46. A. DUTTA and M. E. RYAN: J. Non-Newton. Fluid Mech., 1982, 10, 235.

47. A. GARCIA-REJON, N. ORBEy, and J. M. DEALY: SPE Tech. Papers, 1981, 27, 431.

48. J. M. DEALY and N. ORBEY: AIChE J., 1985, 31, 807.

49. F. H. AXTELl and B. HaWORTH: J. Sci. Soc. Thailand, 1993, 19, 25.

50. M. R. KAMAL, v. TAN, and D. Kalyon: Polym. Eng. Sci., 1981, 21, (6), 331.

51. J. BUSBY and K. Kouba: Presented at Conf. 'Advances in blow moulding', Loughborough, UK, June 1998, Institute of Materials.

52. B. PUKANSZKY, E. FEKETE, and J. KOLARIK: J. Mater. Sci., Lett., 1989, 8, 1040.

53. D. A. TAYLOR and C. D. PAYNTER: Proc. Int. Fillers Symp., Loughborough, UK, 1994.

54. R. HERZIG and W. E. BAKER: J. Mater. Sci., 1993, 24, 6531.

55. A. M. RILEY, C. D. PAYNTER, P. M. McGENITY, and J. M. ADAMS: Plast. Rubber Process. Appl., 1990, 14, (2), 85 . 